\title{
Schopenhauer no Brasil: Análise da presença schopenhaueriana em teses de doutorado e dissertações de mestrado de 1987 a 2018
}

Schopenhauer in Brazil: Analysis of the Schopenhauerian presence in doctoral theses and master's dissertations from 1987 to 2018

Fernando Sá Moreira ${ }^{\mathrm{I}}$

Resumo: O objetivo desta pesquisa é avaliar a presença de Arthur Schopenhauer como tema de dissertações de mestrado e teses de doutorado no Brasil. Essa avaliação é realizada a partir das respostas a quatro perguntas fundamentais: (1) Em que localidades a Pesquisa Schopenhauer se concentra? (2) Em quais níveis da pós-graduação stricto sensu ela ocorre? (3) Quais áreas do conhecimento a produziram e a produzem? (4) Quais são seus temas predominantes? A metodologia empregada é predominantemente quantitativa e consiste na análise dos dados de trabalhos registrados no Catálogo de Teses e Dissertações da Coordenação de Aperfeiçoamento de Pessoal de Nível Superior (Capes).

Palavras-chave: Ética; Metafísica; Estética; Felicidade terrena; Felicidade pura.

Abstract: This study aims to evaluate the presence of Arthur Schopenhauer as object of master's dissertations and doctoral theses in Brazil. The work is based on the answers to four fundamental questions: (1) At what physical locations is Schopenhauer Research localized? (2) At what levels of the stricto sensu postgraduate does it take place? (3) What knowledge fields did participate in the Brazilian Schopenhauer Research? (4) What are its predominant themes? The methodology is predominantly quantitative and consists of the analysis of information about postgraduate works from the Catálogo de Teses e Dissertações (Catalog of Thesis and Dissertations) of the Coordenação de Aperfeiçoamento de Pessoal de Nível Superior (Capes, Coordination for the Improvement of Higher Education Personnel).

Keywords: Schopenhauer research; Theses; Dissertations; Postgraduate studies; Quantitative analysis. 


\section{Introdução}

$\mathrm{Na}$ década de 1990 seria quiçá possível um(a) pesquisador(a) brasileiro(a) do pensamento de Arthur Schopenhauer se propor a conhecer e analisar, qualitativamente, uma a uma todas as teses e dissertações sobre o filósofo produzidas no Brasil. Até o final daquela década, elas não somavam mais do que duas dezenas de produções, que poderiam ser analisadas mesmo em um ou dois anos de trabalho. Sua maior dificuldade seria provavelmente a de empregar todo o esforço e tempo necessário para identificar a existência e acessar todo esse material, já que ele se encontra espalhado pelo território nacional.

A situação onde nos encontramos agora, no final dos anos 2010, é completamente outra. Temos a nossa disposição inúmeras ferramentas de pesquisa e acesso aos dados dessas produções. Isso vale principalmente para as teses e dissertações mais recentes, mas vale lembrar também que muitas universidades brasileiras têm empreendido esforços para digitalizar seus acervos de teses e dissertações mais antigos. E, ainda que nem todo esse material esteja disponível digitalmente, pode-se dizer sem grande receio de incorrer em erro que a esmagadora maioria dos trabalhos de pós-graduação stricto sensu sobre Schopenhauer encontra-se disponível integralmente na internet.

Ou seja, nos encontramos hoje com a dificuldade oposta a do(a) pesquisador(a) dos anos 1990. Ele(a) teria muita dificuldade para obter todos ou quase todos os trabalhos de pós-graduação sobre o filósofo alemão produzidos nas universidades brasileiras, mas, caso os conseguisse, poderia chegar a uma análise qualitativa de todos eles ao cabo de alguns meses. Nós, no entanto, ainda que sejamos capazes de identificar e acessar dezenas de trabalhos em um único dia, caso quiséssemos fazer a leitura integral de todo esse material, levaríamos anos nessa tarefa. Além disso, considerando o ritmo de produção atual dos programas de pós-graduação brasileiros, seria de se esperar que novas dezenas de trabalhos surgissem ao longo desses anos de leitura, o que demandaria ainda mais tempo de análise. Arrisco dizer que hoje beira à impossibilidade a pretensão de conhecer detalhadamente todas as produções de pós-graduação de um único filósofo como Schopenhauer.

Isso não significa, porém, que não seja possível adotar estratégias que permitam alcançar uma visão de conjunto dessas produções. Uma das estratégias possíveis é promover uma abordagem quantitativa desse material. Não é certamente uma abordagem usual dentro da área da filosofia e, com efeito, a maioria dos estudos acadêmicos dessa área, não lança mão desse tipo de análise. ${ }^{1}$ No entanto, é preciso admitir que uma visão de conjunto das teses e dissertações produzidas sobre o filósofo pode servir como uma vantajosa ferramenta auxiliar para o desenvolvimento de pesquisas de cunho mais usual e qualitativo.

Para além do interesse específico na situação atual da Pesquisa Schopenhauer no Brasil, eu tenho particularmente duas outras motivações principais para desenvolver o presente estudo. Em primeiro lugar, quero encontrar informações que me permitam

\footnotetext{
${ }^{1} \mathrm{O}$ mais comum é desenvolver uma narrativa histórica na qual se procura apresentar qualitativamente os trabalhos que são considerados mais relevantes e influentes sobre um(a) filósofo(a), descrevendo brevemente seu contexto de surgimento e também seu legado em sua campo de pesquisa. A vantagem de uma tal abordagem é que ela consegue mais facilmente captar certos sujeitos da pesquisa e seus movimentos no sentido da consolidação de um campo. A desvantagem é que a análise se torna geralmente limitada a quem e àquilo que o(a) analista foi capaz de conhecer e reconhecer pessoal e detalhadamente. Trabalhos com essas características mais qualitativas são, por exemplo, os estudos sobre a recepção de Nietzsche publicados por Frezzatti Jr. (A recepção de Nietzsche na França: da Revue philosophique de la France et de l'Étranger ao período entreguerras), Sánchez (Nietzsche no Rio da Prata) e o estudo sobre a história dos Estudos sobre Schopenhauer publicado por Cacciola, Salviano e Debona (Geschichte und aktuelle Situation der Schopenhauer-Studien in Brasilien).
} 
compreender a dinâmica da produção acadêmica brasileira em programas de pós-graduação stricto sensu, em especial os da área de ciências humanas e filosofia. Em segundo lugar, desejo desenvolver ferramentas e técnicas de pesquisa e análise que permitam atingir uma visão ampla da produção acumulada nesses programas nas últimas décadas, não apenas no tocante a produção sobre um(a) filósofo(a) em particular, mas principalmente sobre temas que atravessem múltiplos filósofos, perspectivas e áreas do conhecimento.

Nenhuma dessas duas motivações se esgota com os resultados apresentados neste artigo. Portanto, pode-se dizer que o presente estudo é o resultado final de uma pesquisa sobre Schopenhauer, ao mesmo tempo que é o resultado parcial de uma pesquisa sobre o produzir-filosofia no Brasil. É preciso também dizer que a presente pesquisa se alimenta dos resultados de uma primeira fase de desenvolvimento desse olhar sobre o produzir-filosofia, que já se materializou na forma de um artigo acadêmico previamente publicado. $O$ primeiro experimento nesse sentido enfocou a produção sobre Nietzsche e encontra-se publicizada na Revista Estudos Nietzsche. ${ }^{2}$

O objetivo do presente estudo é mensurar a presença e a intensidade do tema Schopenhauer em 4 "espaços da pesquisa" na pós-graduação: localidade, nível, área do conhecimento e temática. Para isso, apresento e debato respostas a 4 perguntas sobre a Pesquisa Schopenhauer ${ }^{3}$ no Brasil entre 1987 e 2018:

1. Geograficamente falando, em que localidades essa Pesquisa se concentra?

2. Em quais níveis da pós-graduação stricto sensu ela ocorre?

3. Quais áreas do conhecimento a produziram e a produzem?

4. Quais são seus temas predominantes?

Os dados apresentados neste estudo são o resultado do trabalho sobre as informações disponíveis publicamente no Catálogo de Teses e Dissertações da Coordenação de Aperfeiçoamento de Pessoal de Nível Superior (CTD/Capes) e na Plataforma Sucupira, mantida pelo mesmo órgão. ${ }^{4}$ Todos os dados básicos foram obtidos através do termo de busca "Schopenhauer". Ou seja, o trabalho inicial foi realizado com toda e qualquer dissertação cadastrada no CTD/Capes, em cujos campos de registro (título, resumo, palavras-chave etc.) constasse o termo "Schopenhauer" e suas variações (e.g. "schopenhaueriano", "schopenhaueriana" ou "schopenhauerianismo"). A coleta de dados definitiva no CTD/Capes ocorreu no dia 16 de abril de 2019 e resultou em uma amostra inicial de 354 teses ou dissertações.

Esse resultado inicial bruto não era satisfatório para o trabalho a ser realizado, pois muitos dos registros obtidos eram de teses ou dissertações cuja presença de Schopenhauer era meramente ocasional. Por exemplo, qualquer trabalho que mencione apenas casualmente o termo "Schopenhauer" em seu resumo foi selecionado na amostra. Então, foi

\footnotetext{
${ }^{2}$ SÁ MOREIRA, 2018.

${ }^{3}$ Embora de maneira geral possa ser empregada em sentido mais amplo, a expressão "Pesquisa Schopenhauer" será usada aqui para designar apenas o conjunto das teses, dissertações selecionadas neste estudo e classificadas como "primárias"; eventualmente também o conjunto dos(as) pesquisadores(as) envolvidos(as) nessas produções.

${ }^{4}$ http://catalogodeteses.capes.gov.br/catalogo-teses/ e https://sucupira.capes.gov.br/sucupira/. O banco de dados da Capes que alimenta o CTD/Capes e a Plataforma Sucupira possui registros de teses e dissertações de 1987 em diante.
} 
114 | Schopenhauer no Brasil: Análise da presença schopenhaueriana em teses de doutorado e dissertações de mestrado de 1987 a 2018

necessário realizar uma classificação dos resultados na amostra em "primários" e "secundários". 5

Trata-se, sem dúvida, do procedimento mais sensível da pesquisa. Então, optei por estabelecer critérios fixos de classificação. Foram classificados como "primários" todos os resultados, cujo título não deixava dúvidas de que se tratava de um trabalho sobre Schopenhauer, citando-o nominalmente. Quando o termo "Schopenhauer" surgiu no título da tese ou da dissertação meramente como nome de obra de outro autor, considerei que esse critério de classificação não foi atendido. Por exemplo, trabalhos que mencionam a obra "Schopenhauer como educador" de Friedrich Nietzsche foram considerados trabalhos exclusivamente sobre Nietzsche, exceto quando declaravam explicitamente o desejo de trabalhar a obra focando o diálogo direto com a teoria do filósofo da vontade de vida. Os trabalhos cujo título deixava claro que o objeto principal de estudo era outro(a) pensador(a) e não mencionavam Schopenhauer textualmente foram considerados "secundários". Os demais casos - sem qualquer declaração de referencial teórico no título - foram analisados um a um segundo os dados do resumo.

Essa classificação formou, por fim, uma base de dados de 181 tese ou dissertações classificadas como "primárias" e 173 classificadas como "secundárias". As afirmações a seguir são fruto do trabalho sobre essa base de dados. Salvo quando indicado em contrário, todas as análises a seguir dizem respeito ao conjunto dos 181 trabalhos classificados como "primários" e referenciados no Anexo I do presente artigo.

\section{Geograficamente falando, em que localidades a Pesquisa Schopenhauer se concentra?}

É fato notório que a distribuição das universidades no território brasileiro não é uniforme, tampouco o é a distribuição dos programas de pós-graduação stricto sensu. Com efeito, de acordo com os dados disponíveis no Sistema de Informações Georreferenciadas da Capes (Geocapes), disponível através da Plataforma Sucupira, de um total de 4.177 programas de pós-graduação stricto sensu (PPGs) existentes no Brasil, quase metade está instalada na região Sudeste, que é seguida pela região Sul, Nordeste, Centro-Oeste e Norte (cf. Tabela 1).6 Encontra-se a mesma distribuição em uma proporção parecida ao considerar apenas os PPGs da área de Filosofia,7 nos quais se encontra, como veremos mais adiante, a maior produção de teses e dissertações sobre Schopenhauer.

\footnotetext{
${ }^{5}$ Obviamente, a classificação não diz respeito à qualidade da tese ou dissertação em questão. Trata-se apenas de selecionar uma amostra de interesse desta pesquisa em particular. Ou seja, "primário" ou "secundário" podem ser lidos aqui como "primário para esta pesquisa em particular" ou "secundário para esta pesquisa em particular”. É o caso também de fazer a seguinte observação: o CTD/Capes é composto por milhares de dados de teses e dissertações cadastradas pelos próprios programas de pós-graduação na Plataforma Sucupira. Infelizmente, há muitos erros de digitação nesses registros, o que me obrigou a fazer ajustes manuais nos registros sempre que identifiquei algum equívoco. Das 354 teses e dissertações da amostra bruta, ajustei manualmente os dados de 59.

${ }^{6}$ Os dados apresentados a seguir são de 2016. De acordo com as informações disponíveis no Geocapes (https://geocapes.capes.gov.br/geocapes/), quando do levantamento de dados para a elaboração este artigo, as informações tinham sido atualizadas em 22/03/2018.

${ }^{7}$ A referência à área de Filosofia ou aos PPGs da área de Filosofia deve ser entendida aqui sempre no sentido da "área de conhecimento da Filosofia”. Ou seja, pensa-se aqui nos PPGs de "Filosofia" em específico, mas também "Lógica e Metafísica”, "Estética e Filosofia da Arte” etc.
} 


\begin{tabular}{|c|c|c|c|c|c|c|c|c|c|c|}
\hline & \multicolumn{2}{|c|}{ Norte } & \multicolumn{2}{|c|}{ Nordeste } & \multicolumn{2}{|c|}{ Centro-Oeste } & \multicolumn{2}{|c|}{ Sudeste } & \multicolumn{2}{|c|}{ Sul } \\
\hline $\begin{array}{r}\text { Geral } \\
\text { Filosofia }\end{array}$ & $\begin{array}{c}223 \\
1\end{array}$ & $\begin{array}{l}5,44 \% \\
2,27 \%\end{array}$ & $\begin{array}{c}831 \\
8\end{array}$ & $\begin{array}{l}20,26 \% \\
18,18 \%\end{array}$ & $\begin{array}{c}332 \\
4\end{array}$ & $\begin{array}{l}8,10 \% \\
9,09 \%\end{array}$ & $\begin{array}{c}1836 \\
19\end{array}$ & $\begin{array}{l}44,77 \% \\
43,18 \%\end{array}$ & $\begin{array}{c}879 \\
12\end{array}$ & $\begin{array}{l}21,43 \% \\
27,27 \%\end{array}$ \\
\hline $\begin{array}{r}\text { Geral } \\
\text { Filosofia }\end{array}$ & $\begin{array}{c}82 \\
0\end{array}$ & $\begin{array}{l}3,76 \% \\
0,00 \%\end{array}$ & $\begin{array}{c}335 \\
4\end{array}$ & $\begin{array}{l}15,35 \% \\
16,67 \%\end{array}$ & $\begin{array}{c}159 \\
1\end{array}$ & $\begin{array}{l}7,29 \% \\
4,17 \%\end{array}$ & $\begin{array}{c}1143 \\
10\end{array}$ & $\begin{array}{l}52,38 \% \\
41,67 \%\end{array}$ & $\begin{array}{c}463 \\
9\end{array}$ & $\begin{array}{l}21,22 \% \\
37,50 \%\end{array}$ \\
\hline $\begin{array}{rr}\text { Total de PPGs } \\
\\
\\
\text { Feral } \\
\text { Filosofia }\end{array}$ & $\begin{array}{c}227 \\
1\end{array}$ & $\begin{array}{l}5,43 \% \\
2,22 \%\end{array}$ & $\begin{array}{c}846 \\
9\end{array}$ & $\begin{array}{l}20,25 \% \\
20,00 \%\end{array}$ & $\begin{array}{c}340 \\
4\end{array}$ & $\begin{array}{l}8,14 \% \\
8,89 \%\end{array}$ & $\begin{array}{c}1875 \\
19\end{array}$ & $\begin{array}{l}44,89 \% \\
42,22 \%\end{array}$ & $\begin{array}{c}889 \\
12\end{array}$ & $\begin{array}{l}21,28 \% \\
26,67 \%\end{array}$ \\
\hline
\end{tabular}

Tabela 1: Distribuição de PPGs por Região. Fonte: Geodados/Capes. Elaboração do autor.

A tabela acima mostra o número absoluto de PPGs em cada região ao lado do percentual que esse número representa no total de PPGs do país. Programas com cursos de mestrado e doutorado são contabilizados duplamente, tanto no número de mestrados, quanto no de doutorados.

Nota-se através desses números que mais de 85\% dos PPGs do Brasil encontram-se nas regiões Sudeste, Sul e Nordeste. Também é relevante observar ainda que a proporção de doutorados na área de Filosofia na região Sul aproxima-se bastante da proporção da região Sudeste (37,5\% dos doutorados estão na região Sul e $41,67 \%$ na região Sudeste). Trata-se de um desvio gritante entre a distribuição de PPGs da área de Filosofia e a distribuição do número de PPGs em geral. Ao passo que, no tocante aos doutorados, as regiões Norte e Centro-Oeste encontram-se mesmo abaixo da média de PPGs em geral.

Em um cenário como esse, é esperado que a maior parte das produções acadêmicas na forma de dissertações de mestrado e teses de doutorado sobre Schopenhauer sejam apresentadas precisamente nas regiões com maior número de programas. E, de fato, pode-se verificar no gráfico a seguir que essa expectativa não é de forma alguma frustrada. $\mathrm{Na}$ verdade, constatamos que ela evidencia que a Pesquisa Schopenhauer se concentra em uma proporção ainda maior do que a de PPGs nas regiões Sudeste (50,83\% da Pesquisa) e Sul (27,07\% da Pesquisa). O Nordeste brasileiro mantém ainda uma produção significativa $(18,78 \%)$, mas já em uma proporção menor do que a de PPGs que possui. Na sequência estão as regiões Centro-Oeste $(2,21 \%)$ e Norte $(1,10 \%)$. O gráfico a seguir mostra como essa produção está distribuída pelos estados brasileiros e pelo distrito federal. 


\section{Pesquisa Schopenhauer por UF}

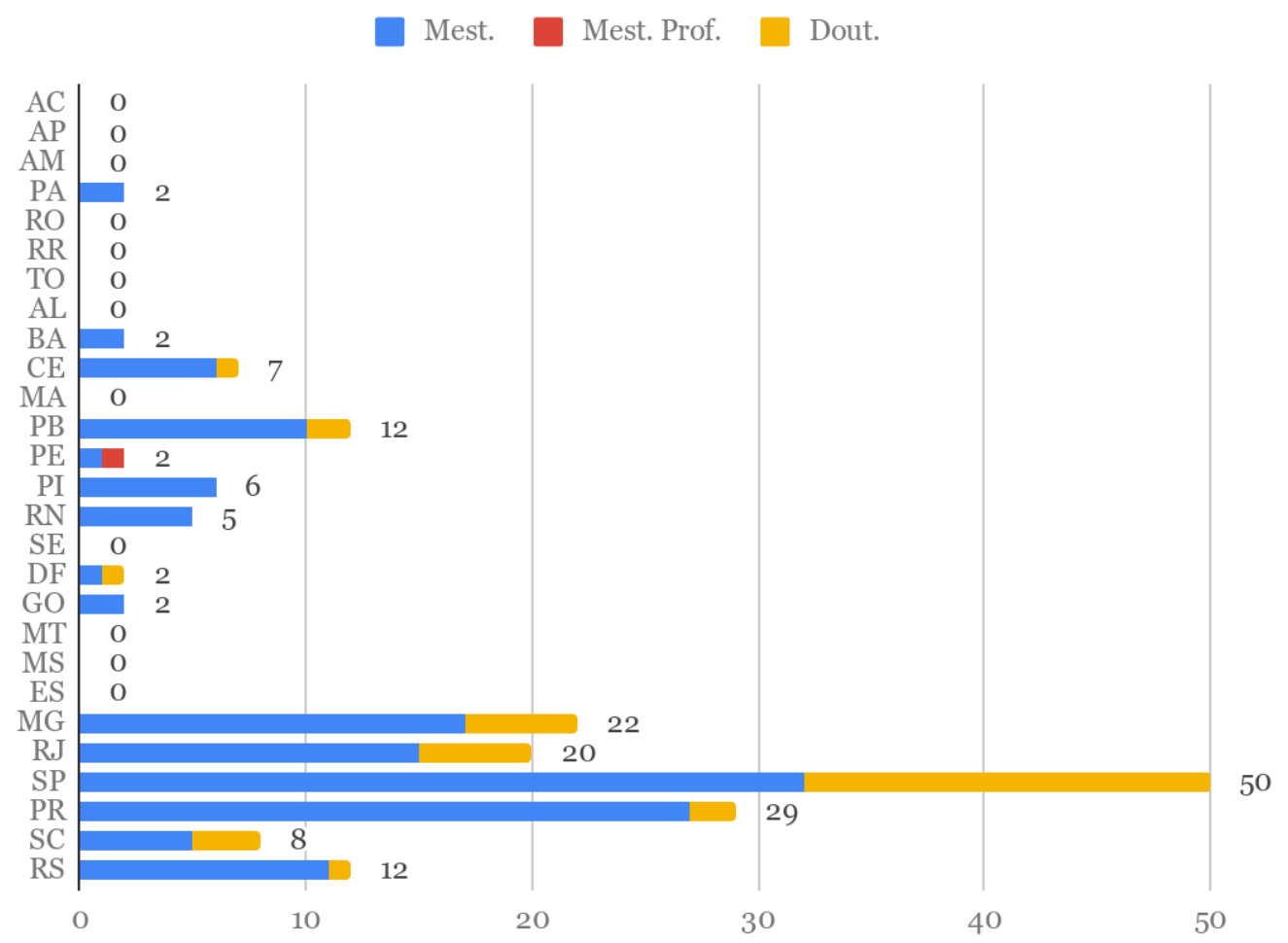

Gráfico 1: Distribuição de Teses e Dissertações sobre Schopenhauer por Unidade Federativa. Fonte: CTD/Capes. Elaboração do autor.

De acordo com o gráfico acima, os estados brasileiros com maior número de produções na Pesquisa Schopenhauer são São Paulo (com 50 teses ou dissertações), seguido por Paraná (com 29), Minas Gerais (com 22), Rio de Janeiro (com 20) e, empatados na quinta posição, os estados do Rio Grande do Sul e Paraíba (12 cada). O estado de São Paulo é, de longe, aquele que mais produz sobre o filósofo alemão, inclusive com um número bastante expressivo de teses de doutorado: aproximadamente 1 de cada 3 teses de doutorado sobre esse tema são defendidas no estado. De fato, somadas teses e dissertações, São Paulo produziu até agora mais do que o dobro de cada uma das outras unidades federativas, com exceção do Paraná. Mas, mesmo neste último caso, a produção paulista é $86,2 \%$ maior do que a paranaense.

Comparar esses dados da Pesquisa Schopenhauer com os dados da Pesquisa Nietzsche nos leva a uma primeira suspeita do presente estudo, que é fortalecida pelas análises das seções a seguir. Embora esteja muito associada a Pesquisa Nietzsche (cf. Seção 4), a Pesquisa Schopenhauer parece possuir características próprias e ocupa espaços próprios na pós-graduação no Brasil. Em um estudo anterior sobre a Pesquisa Nietzsche entre 2010 e $2018,{ }^{8}$ a distribuição das teses e dissertações pelo território nacional apresentou uma configuração regional semelhante à da Pesquisa Schopenhauer, porém a análise da distribuição da produção nas unidades federativas teve um resultado razoavelmente distinto. Segundo esse estudo, na Pesquisa Nietzsche, os estados mais produtivos são Rio de 
Janeiro (com 75 teses ou dissertações), São Paulo (com 70), Minas Gerais (com 45), Paraná (com 36) e Rio Grande do Sul (com 30). 9

Ao todo, 42 diferentes Instituições de Ensino Superior (IES) abrigaram defesas de teses ou dissertações da Pesquisa Schopenhauer (Tabela 2). No entanto, quase 6o\% das pesquisas em geral e pouco mais de $76 \%$ das teses de doutorado foram defendidas em apenas 10 dessas instituições, como se pode observar abaixo:

\begin{tabular}{|l|c|c|c|c|}
\hline Sigla & Mestrado & $\begin{array}{c}\text { Mestrado } \\
\text { Profissional }\end{array}$ & Doutorado & Total \\
\hline USP & 13 & 0 & 11 & 24 \\
\hline UNICAMP & 10 & 0 & 5 & 15 \\
\hline UFPB & 10 & 0 & 2 & 12 \\
\hline PUC/PR & 10 & 0 & 1 & 11 \\
\hline UFMG & 5 & 0 & 4 & 9 \\
\hline UFSC & 5 & 0 & 3 & 8 \\
\hline UFPR & 8 & 0 & 0 & 8 \\
\hline UFRJ & 5 & 0 & 2 & 7 \\
\hline UFPI & 6 & 0 & 0 & 6 \\
\hline UEL & 5 & 0 & 1 & 5 \\
\hline UFOP & 5 & 0 & 0 & 5 \\
\hline UFRN & 5 & 0 & 0 & 4 \\
\hline PUC/SP & 2 & 0 & 2 & 5 \\
\hline UECE & 4 & 0 & 0 & 7 \\
\hline Outras & 49 & 1 & 0 & 57 \\
\hline
\end{tabular}

Tabela 2: Distribuição da Pesquisa Schopenhauer por IES. Fonte: CTD/Capes. Elaboração do autor.

Tendo sido identificadas as 10 IES mais produtivas, busquei identificar o ritmo com que essas universidades abrigaram as teses e dissertações da Pesquisa Schopenhauer ao longo do tempo. Para que essa identificação fosse possível, elaborei o gráfico a seguir, o qual traça de maneira cumulativa a produção de cada universidade ao longo do tempo. Ou seja, a posição de cada ponto na linha que representa cada universidade é o resultado da soma das produções daquele momento e todas as produções anteriores. Por exemplo, a posição da linha que designa a produção da USP em 2010 indica que essa universidade produziu 15 trabalhos entre 1989 e 2010 ; e não que ela teria abrigado 15 defesas somente no ano de 2010. $O$ resultado é o que se segue:

${ }^{9} \mathrm{O}$ levantamento de dados desse estudo sobre a Pesquisa Nietzsche foi realizado em 12 de julho de 2018 , portanto, os números podem ser ligeiramente diferentes quando consideradas as defesas realizadas no segundo semestre de 2018 que, obviamente, não são contabilizadas na análise. 
118 | Schopenhauer no Brasil: Análise da presença schopenhaueriana em teses de doutorado e dissertações de mestrado de 1987 a 2018

\section{Produtividade das 10 instituições com mais Teses e Dissertações defendidas}

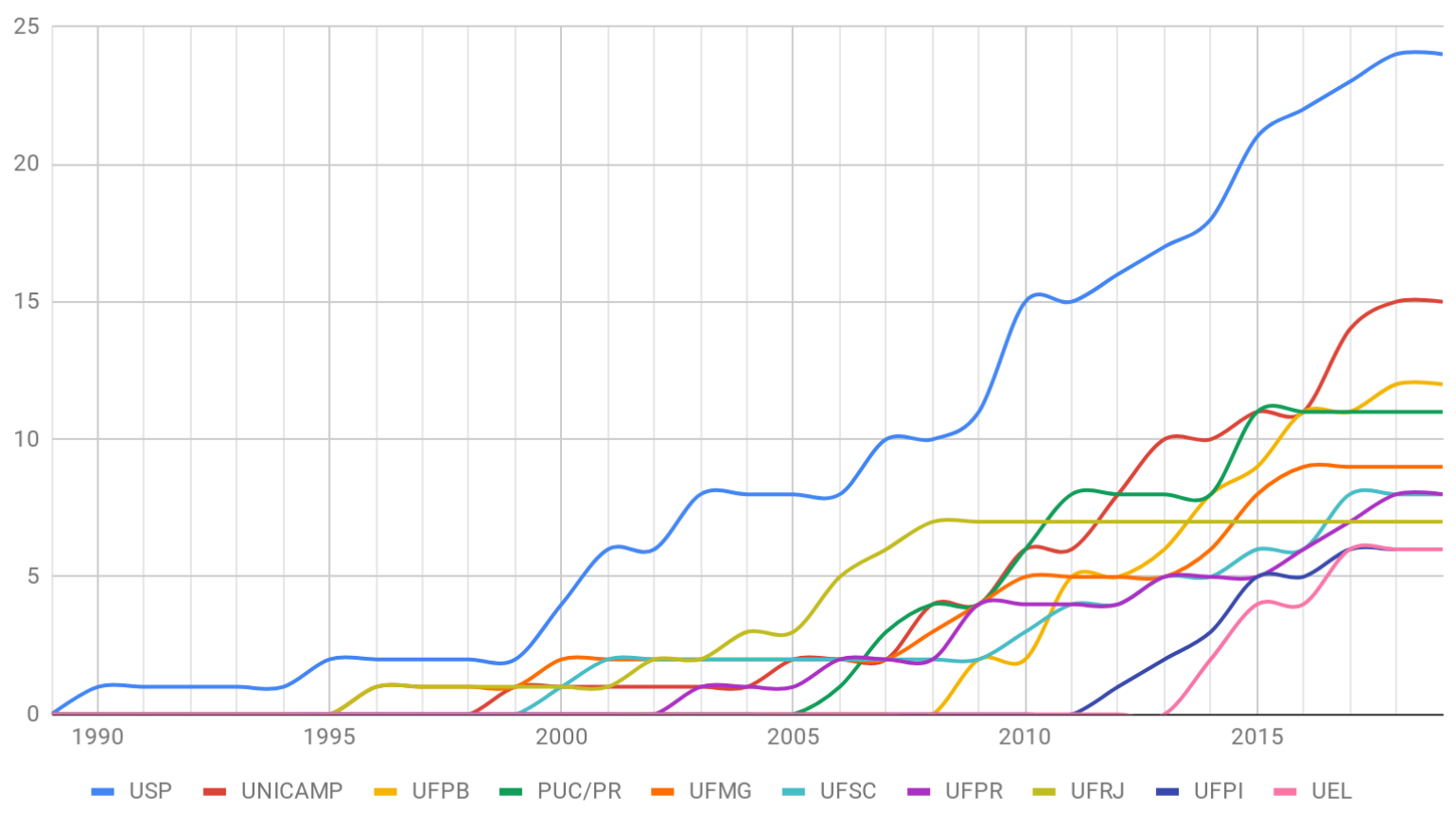

Gráfico 2: Produtividade cumulativa da Pesquisa Schopenhauer por IES no período 1989-2018. Fonte: CTD/Capes. Elaboração do autor.

Constata-se através do gráfico que há de fato um predomínio da Universidade de São Paulo ao longo do tempo na Pesquisa Schopenhauer. Ela não só está entre as primeiras universidades apresentar trabalhos de pós-graduação sobre o filósofo alemão, mas também tem mantido constância na produção desde ao menos o ano 200o. Um elemento a se observar, porém, diz respeito a alternância de posições das demais universidades. A UFRJ, por exemplo, encontra-se também entre as primeiras universidades a produzir sobre o pensador da vontade de vida, e de fato, em 2008 era a segunda universidade com maior produção entre as 10 selecionadas para análise. Porém, na década seguinte não abrigou mais defesas sobre o tema e hoje pode ser considera apenas a 8a IES mais produtiva.

Outra trajetória interessante é a da PUC/PR. O início de sua produção é relativamente tardio e remonta a 2006 somente. Entretanto, o ritmo de defesas foi razoavelmente alto, a ponto da instituição se tornar por duas vezes a segunda universidade com maior número de defesas abrigadas (em 2011 e no período de 2015-2016). Essa produtividade não se manteve e mais recentemente a UNICAMP e a UFPB passaram a ocupar a segunda e a terceira posições, respectivamente.

$\mathrm{O}$ caso da UFPB chama a atenção às 3 universidades do gráfico com início de produção mais tardio: Universidade Federal da Paraíba (2009), Universidade Federal do Piauí (2012) e Universidade Estadual de Londrina (2014). Apesar de suas defesas mais antigas remontarem a menos de uma década, a constância de defesas as coloca em posição de destaque hoje entre as IES do país com produção na Pesquisa Schopenhauer.

É preciso dizer que não se trata aqui propriamente de produzir um ranking das universidades com o objetivo de enaltecer uma ou outra instituição, em detrimento das demais. Não se trata também de pretender qualquer dedução de qualidade dos trabalhos a partir da quantidade de defesas acumuladas em cada IES. O que mais me interessa na análise da produtividade das universidades ao longo do tempo é dispor de dados que possam 
complementar a percepção das trajetórias de instituições e de pesquisadoras(es) sobre Schopenhauer.

Não está no escopo deste artigo fazer essa análise mais fina e qualitativa, por ora é suficiente para os propósitos do presente estudo identificar as trajetórias quantitativas de cada IES. Vale dizer, no entanto, que as cessões súbitas ou aumentos repentinos de produtividade podem indicar pontos de viragem importantes na história da Pesquisa Schopenhauer, como a criação de grupos de pesquisa, publicações ou traduções de obras de impacto, morte, transferência de instituição ou mudança de temas de um(a) pesquisador(a) relevante, criação de um novo PPG com tendências temáticas favoráveis etc.

\section{Em quais níveis de pós-graduação stricto sensu a Pesquisa Schopenhauer ocorre no Brasil?}

A Pesquisa Schopenhauer na pós-graduação brasileira tem mais de 30 anos de história. A princípio, o CTD/Capes registra quase a totalidade dos trabalhos defendidos no Brasil. Segundo o portal Dados Abertos da Capes, pertencente à Plataforma Sucupira ${ }^{10}$, o banco de dados que alimenta o CTD/Capes mantém registros das informações da pósgraduação desde 1987. Quanto ao período anterior à essa data, tenho conhecimento da existência de apenas uma dissertação de mestrado defendida sobre o filósofo da vontade de vida no Brasil. Trata-se da dissertação de mestrado de Maria Lúcia Cacciola, intitulada " $A$ crítica da razão no pensamento de Schopenhauer" e defendida no programa de pósgraduação em Filosofia da Universidade de São Paulo em 1982." De acordo com o CTD/Capes, no período pós-1987, o primeiro trabalho de pós-graduação stricto sensu sobre o pensador alemão no Brasil foi a dissertação de mestrado de Victor Hugo Guimarães Rodrigues, sob o título de "Platão e Schopenhauer: artistas diante do espelho", defendida em 1989 no PPG em Filosofia da UFSM. A primeira tese de doutorado defendida foi a bem conhecida obra "Schopenhauer e a questão do dogmatismo" de Maria Lúcia Cacciola, surgida no PPG em Filosofia da USP em 1990.

Os anos seguintes foram marcados pela baixa produção de pesquisas de pósgraduação sobre o filósofo alemão. O CTD/Capes registra apenas 5 dissertações de mestrado e nenhuma tese de doutorado no período de 1991-1999 (cf. Gráfico 3). Porém a partir de 2000 essa situação mudou radicalmente. Em apenas 2 anos (2000 e 2001) a Pesquisa Schopenhauer mais do que dobrou o número de defesas registradas com 6 dissertações de mestrado e 3 teses de doutorado no total. Pode-se dizer que a primeira década do século XXI foi o momento de consolidação da presença de Schopenhauer na pós-graduação no Brasil, tanto em nível de mestrado quanto em nível de doutorado. A década seguinte, é marcada por fortes oscilações na quantidade de pesquisas a cada ano, mas, de modo geral, reafirma e intensifica a posição consolidada na década anterior.

\footnotetext{
${ }^{10}$ Disponível em: <https://dadosabertos.capes.gov.br/dataset>. Acesso em 1 o de maio de 2019.

${ }^{11}$ CACCIOLA, SALVIANO, DEBONA, Geschichte und aktuelle Situation der Schopenhauer-Studien in Brasilien. Para todos os efeitos, essa dissertação não foi contabilizada nos dados estatísticos do presente estudo.
} 


\section{Teses e Dissertações sobre Schopenhauer}

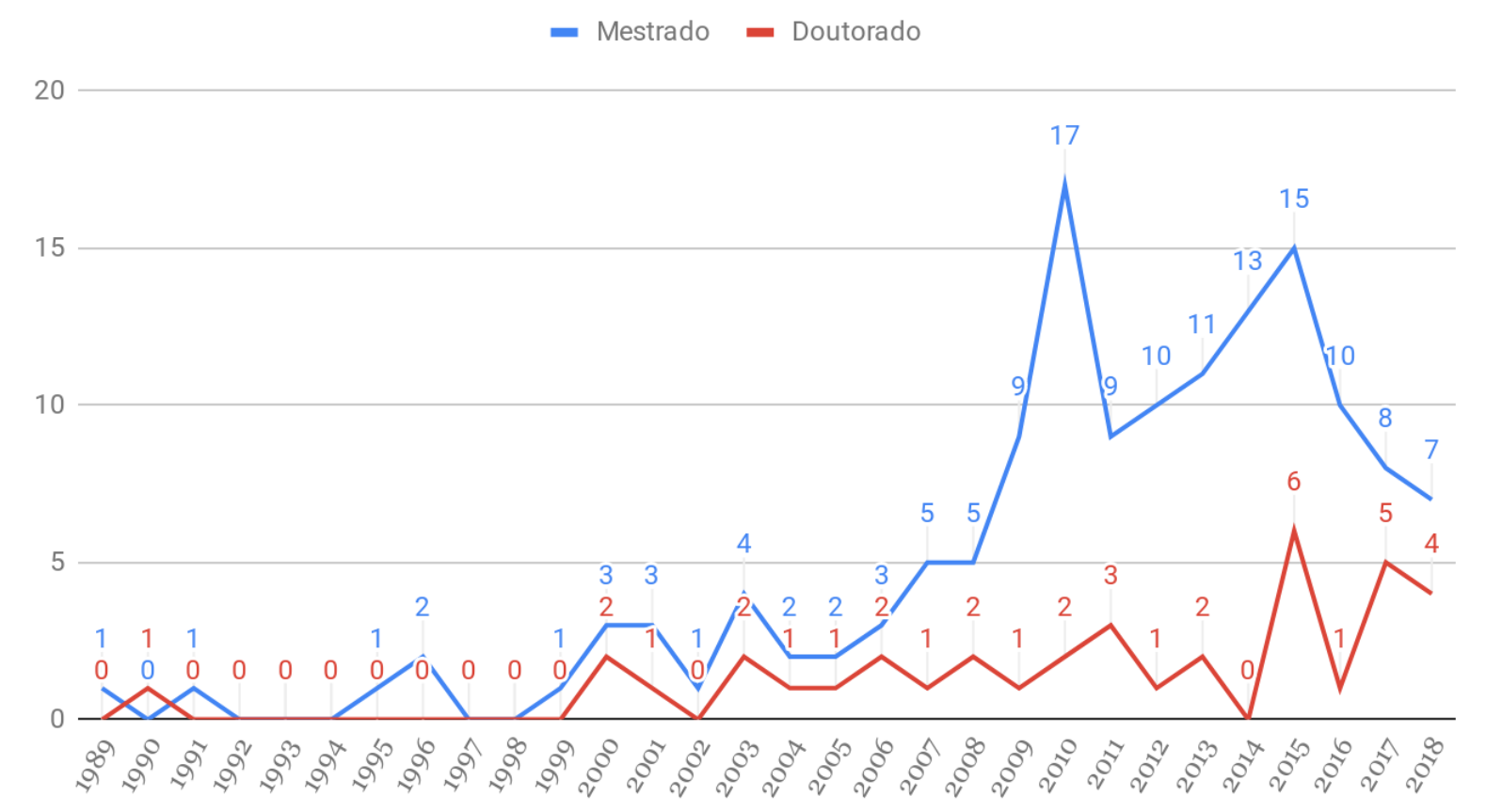

Gráfico 3: Distribuição de Teses e Dissertações sobre Schopenhauer ao longo do tempo (1989-2018). Fonte: CTD/Capes. Elaboração do autor.

O gráfico evidencia dois momentos em destaque na produção da Pesquisa Schopenhauer, as imediações dos anos de 2010 e de 2015, que marcam seus anos mais produtivos até agora. $\mathrm{O}$ ano de 2015 em particular não só apresenta um grande número de dissertações de mestrado, mas também marca o ápice das defesas de teses de doutorado em um único ano. Mas, nota-se também que após esses períodos de alta súbita, a produção sobre o filósofo tem apresentado uma tendência de queda. É preciso afirmar, contudo, que não se pode dizer efetivamente que tenha cessado repentinamente o interesse dos pesquisados no filósofo. A explicação que particularmente me parece mais provável é a de que se trata - após um período de uma alta súbita e atípica - de um retorno à tendência normal que marca a produção depois do ano 2000.

Para além disso, uma característica interessante da Pesquisa Schopenhauer é o percentual razoavelmente alto de doutoramentos em relação ao total da produção, em especial nos períodos de 2000-2006 e 2015-2018. Para todo o período analisado nesta pesquisa (1987-2018), o percentual médio supera os $20 \%$ da produção total. ${ }^{12}$

O Painel de Informações Quantitativas da Capes somente nos fornece informações datadas de 2013 em diante. Com base nesses dados, podemos afirmar que, no período 20132018, teses de doutorado defendidas no Brasil em todas as áreas somadas compõe aproximadamente $25 \%$ dos trabalhos de pós-graduação stricto sensu do país. Especificamente na área da Filosofia, esse percentual atinge aproximadamente 26\%. É preciso ressaltar que uma comparação entre esses quantitativos de produção com os percentuais da produção sobre Schopenhauer não é perfeitamente adequado, pois os dados do Painel não possuem nenhum recorte temático. Mas, ainda assim, pode-se observar que a

\footnotetext{
${ }^{12}$ Nesta seção em particular, inclusive no Gráfico 3 e nas análises a seguir, considero em conjunto a produção de mestrados e mestrados profissionais sobre Schopenhauer. Faço essa opção porque, em verdade, existe apenas 1 trabalho de mestrado profissional sobre o filósofo alemão, defendido em 2015 por Maria de Fátima Silva no PPG em Gestão Empresarial da Faculdade Boa Viagem.
} 
pesquisa sobre o filósofo alemão tem se aproximado desses números. Entre 2013 e 2018 a taxa de doutorados com temática schopenhaueriana atingiu pouco mais de $21 \%$, em tendência de crescimento. Com efeito, caso seja analisado apenas o período de 2015-2018, o percentual chega a pouco mais de $28 \% .^{13}$

Seria preciso um estudo mais preciso sobre a trajetória formativa das pesquisadoras e pesquisadores do pensamento schopenhaueriano para poder fazer qualquer afirmação conclusiva, contudo esses números sugerem duas hipóteses não exclusivas entre si: (a) que uma quantia razoável de pesquisadores(as) têm migrado de outros temas de mestrado para pesquisas sobre o pensamento schopenhaueriano no doutorado; e/ou (b) que é alto o índice de mestres com pesquisa em Schopenhauer que concluem também doutoramentos sobre seu pensamento.

Foge ao escopo do presente artigo investigar essas hipóteses a fundo. Ainda assim, vale mencionar que, se a hipótese da existência de uma alta taxa de engajamento de mestres com pesquisa sobre Schopenhauer em doutorados estiver correta, poder-se-ia explicar parcialmente o aumento de defesas de doutorado a partir de 2015. Uma parte significativa desses doutoramentos seria consequência do reingresso nos PPGs brasileiros das(os) pesquisadoras(es) com mestrados defendidos no primeiro grande pico de defesas, por volta do ano de 2010. Ainda no caso dessa hipótese estar correta, a mesma lógica ajudaria a entender por que o crescimento súbito no número de mestrados defendidos nas imediações do ano de 2010 não foi acompanhado por um aumento semelhante no número de doutorados: porque o número de defesas de mestrado no período anterior à 2010, sendo já próximo do número de doutorados, não sustentaria um aumento súbito dos doutorados por volta de 2010.

Ainda trabalhando com a hipótese da alta taxa de engajamento de mestres sobre Schopenhauer em doutorados sobre Schopenhauer, podemos arriscar também uma previsão. O pico produtivo ao redor do ano de 2015 formou um número de mestres suficientes para supostamente sustentar um novo crescimento - ou ao menos uma manutenção da alta produção - nas defesas de doutorado sobre Schopenhauer por volta de 2020. Então, caso a dinâmica de formação de doutores no Brasil não seja influenciada fortemente por fatores outros - tais como desinvestimento no setor da educação pública brasileira, diminuição do número de bolsas, do número de vagas em doutorados, do acesso efetivo de discentes, redução do número de programas, da expectativa de empregabilidade etc. -, o número de teses defendidas sobre Schopenhauer deve se manter acima da média registrada no período de 2000-2014, quiçá com crescimento em relação ao período 2016-2018.

\section{Quais áreas do conhecimento produziram e produzem a Pesquisa Schopenhauer?}

Após compreender a distribuição da Pesquisa Schopenhauer pelo território brasileiro e visualizar como ela se distribui nos diferentes níveis da pós-graduação, interessa agora buscar compreender em quais áreas de conhecimento os pesquisadores e as pesquisadoras têm buscado fazer sua formação. Não há dúvida que existe uma expectativa de que os PPGs de Filosofia sejam os mais procurados, porém, é importante compreender a intensidade em

\footnotetext{
${ }^{13}$ A título de comparação, o estudo anteriormente realizado (MOREIRA, 2018) mostrou que o percentual de teses de doutorados na Pesquisa Nietzsche no período 2010-2017 foi de 17,60\%, com uma clara tendência de queda do percentual de doutorados em relação aos mestrados em todo o período (e.g. em 2017, o percentual de teses foi de apenas $12,5 \%$ ).
} 
122 | Schopenhauer no Brasil: Análise da presença schopenhaueriana em teses de doutorado e dissertações de mestrado de 1987 a 2018

que esses PPGs são procurados e também que outras áreas têm abrigado o diálogo com o filósofo de Frankfurt, ainda que de forma minoritária.

Para que fosse possível chegar a uma visão de conjunto sobre esse ponto, realizei um levantamento nas teses e dissertações considerando o nome do PPG, no qual se apresentou cada trabalho. Porém, dada a variedade de programas, procedi seu agrupamento em grupos temáticos. Os dados encontram-se dispostos na tabela abaixo. $\mathrm{O}$ número entre parênteses antes do nome da área na primeira coluna indica o número de diferentes nomenclaturas de programas agrupados sob uma mesma rubrica. “(3) Filosofia (e áreas correlatas)”, por exemplo, agrupa 3 nomenclaturas de programas de áreas pertencentes à Filosofia em geral: programas em "Filosofia”, em "Estética e Filosofia da Arte” e em "Lógica e Metafísica”. Os números entre parênteses na coluna "Instituições" indicam o número de trabalhos de pósgraduação stricto sensu defendidos em cada IES listada na área em questão.

\begin{tabular}{|c|c|c|c|c|c|c|c|c|c|}
\hline Área & Me & rado & & Prof. & Dot & orado & & tal & Instituiçōes \\
\hline $\begin{array}{l}\text { (1) Arquitetura e } \\
\text { Urbanismo }\end{array}$ & 0 & $0,00 \%$ & 0 & $0,00 \%$ & 1 & $2,63 \%$ & 1 & $0,55 \%$ & (1) UNB \\
\hline \begin{tabular}{|l} 
(1) Ciência da \\
Informação
\end{tabular} & 0 & $0,00 \%$ & 0 & $0,00 \%$ & 1 & $2,63 \%$ & 1 & $0,55 \%$ & (1) UFPB \\
\hline $\begin{array}{l}\text { (3) Ciência(s) da(s) } \\
\text { Religião(ões) }\end{array}$ & 6 & $4,23 \%$ & 0 & $0,00 \%$ & 1 & $2,63 \%$ & 7 & $3,87 \%$ & $\begin{array}{l}\text { (1) PUC/MG ** (1) PUC/SP ** (3) UFJF ** (2) } \\
\text { UFPB }\end{array}$ \\
\hline (1) Direito & 2 & $1,41 \%$ & 0 & $0,00 \%$ & 1 & $2,63 \%$ & 3 & $1,66 \%$ & (3) UFMG \\
\hline (1) Educação & 6 & $4,23 \%$ & 0 & $0,00 \%$ & 0 & $0,00 \%$ & 6 & $3,31 \%$ & $\begin{array}{l}\text { (1) UCS } * * \text { (1) UFBA } * * \text { (1) UFC } * * \text { (1) UFRN } * * \\
\text { (1) UFSC } \text { US }^{* *} \text { (1) UNICAMP }\end{array}$ \\
\hline (1) Enfermagem & 0 & $0,00 \%$ & 0 & $0,00 \%$ & 1 & $2,63 \%$ & 1 & $0,55 \%$ & (1) UFSC \\
\hline $\begin{array}{l}\text { (1) Engenharia de } \\
\text { Produção }\end{array}$ & 1 & $0,70 \%$ & 0 & $0,00 \%$ & 0 & $0,00 \%$ & 1 & $0,55 \%$ & (1) UFRJ \\
\hline $\begin{array}{l}\text { (3) Filosofia (e áreas } \\
\text { correlatas) }\end{array}$ & 119 & $83,80 \%$ & 0 & $0,00 \%$ & 30 & $78,95 \%$ & 149 & $82,32 \%$ & 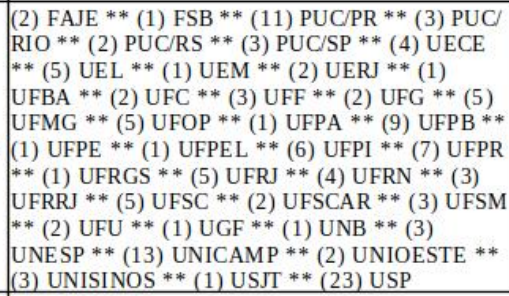 \\
\hline (1) Geografia & 1 & $0,70 \%$ & 0 & $0,00 \%$ & 0 & $0,00 \%$ & 1 & $0,55 \%$ & (1) UNICAMP \\
\hline (1) Gestão Empresarial & 0 & $0,00 \%$ & 1 & $100,00 \%$ & 0 & $0,00 \%$ & 1 & $0,55 \%$ & (1) FBV \\
\hline $\begin{array}{l}\text { (6) Letras (e áreas } \\
\text { correlatas) }\end{array}$ & 6 & $4,23 \%$ & 0 & $0,00 \%$ & 3 & $7,89 \%$ & 9 & $4,97 \%$ & $\begin{array}{l}\text { (1) UEL }{ }^{* *}(1) \text { UEM } * *(1) \text { UERJ } * *(1) \text { UFMG } \\
\text { ** (1) UFPA ** (1) UFRGS ** (1) UFRJ ** (1) } \\
\text { UFSC } * * \text { (1) USP }\end{array}$ \\
\hline (1) Música & 1 & $0,70 \%$ & 0 & $0,00 \%$ & 0 & $0,00 \%$ & 1 & $0,55 \%$ & (1) UFPR \\
\hline
\end{tabular}

Tabela 3: Teses e Dissertações de acordo distribuídas nos diferentes programas de pós-graduação brasileiros. Fonte: CTD/Capes. Elaboração do autor.

Os dados dessa tabela nos permitem concluir não apenas que as expectativas sobre a presença maior de pesquisas da área de Filosofia foram satisfeitas, mas também que a Pesquisa Schopenhauer está radicalmente concentrada nessa área. Mais de $82 \%$ dos trabalhos defendidos por pesquisadores de Schopenhauer estão nesses programas, perfazendo o total de 119 dissertações de mestrado e 30 teses de doutorado ao longo de 30 anos. O restante da produção está bastante dispersa em outros programas, dentre as quais se destacam os da área de Letras com 4,97\% da produção (9 trabalhos no total), Ciência(s) da(s) Religião(ões) com 3,87\% (7 trabalhos), Educação com 3,31\% (6 trabalhos) e Direito 1,66\% (3 trabalhos). Todas as demais áreas possuem apenas 1 trabalho publicado cada.

De modo geral, pode-se dizer que, ainda que os números específicos fossem difíceis de prever, provavelmente ninguém ficará surpreso com a revelação do conjunto das áreas mais produtivas da Pesquisa Schopenhauer. Quase todas são ligadas às ciências humanas; a única exceção, Direito, também não surpreende, pois é uma ciência social aplicada com longo histórico de aproximações com as ciências humanas. Por outro lado, talvez cause 
algum estranhamento nos(as) estudiosos(as) do pensador alemão ver seu nome associado a pesquisas em Engenharia de Produção, Gestão Empresarial, Geografia, Enfermagem ou Ciência da Informação.

Infelizmente, percebe-se que à exceção da área de Filosofia, todas as demais não contam hoje com o que se poderia chamar de uma presença consolidada da pesquisa sobre Schopenhauer em seus programas. Considerando a data de defesa das teses e dissertações nesses PPGs, nota-se que não há continuidade nas produções. Mesmo a área de Direito, cuja produção deriva de uma única universidade possui visíveis quebras de produtividade sobre o tema em questão. De acordo com os dados disponíveis no CTD/Capes, o PPG em Direito da UFMG contribuiu pela primeira vez com a Pesquisa Schopenhauer em 2008 com 1 tese de doutorado, no entanto, só voltou a apresentar defesas sobre o filósofo 6 anos depois, com 1 dissertação de mestrado em 2014 e outra em 2016.

Das áreas de conhecimento mais produtivas, uma me chamou particular atenção: a Educação. Certamente, também não é possível dizer que a Pesquisa Schopenhauer se encontra consolidada nesse campo. O CTD/Capes aponta a existência de apenas 6 trabalhos em mais de 30 anos de pesquisas registradas, todos os trabalhos em nível de mestrado e defendidos em 6 universidades diferentes. O último trabalho da área foi defendido em 2013. Porém, curiosamente, é a única das áreas mais produtivas que contraria a dinâmica regional da Pesquisa Schopenhauer. Em todas as áreas com mais de um trabalho publicado, o Sudeste é mais produtivo do que as demais regiões do país; exceto na Educação. Dos 6 trabalhos publicados 3 foram defendidos na região Nordeste, 2 na região Sul e apenas 1 teve lugar na região Sudeste.

Sendo de longe a Filosofia a área mais produtiva e consolidada da Pesquisa Schopenhauer, recorro agora a uma análise de sua dinâmica interna. Pretendo responder às duas perguntas a seguir:

I. O quão representativa é a Pesquisa Schopenhauer no cenário geral da área de Filosofia?

II. A representação da Pesquisa Schopenhauer tem apresentado uma tendência de aumento ou de decréscimo?

Para encontrar respostas a essas questões, lanço mão novamente dos dados do Painel de Informações Quantitativa da Capes. É preciso recordar que os dados só estão disponíveis a contar do ano de 2013. Importa também dizer que a Capes atualiza frequentemente suas informações de modo a eventualmente gerar pequenas modificações mesmo nos quantitativos de anos mais remotos. Ainda assim, trata-se possivelmente da fonte de dados mais completa e mais segura disponível para esse tipo de pesquisa atualmente no Brasil. Os dados dispostos a seguir foram coletados em 26 de abril de 2019 e revelam o resultado do comparativo da produção sobre o filósofo alemão diante da produção geral da área de conhecimento de Filosofia. 
124 | Schopenhauer no Brasil: Análise da presença schopenhaueriana em teses de doutorado e dissertações de mestrado de 1987 a 2018

\begin{tabular}{c|ccc|ccc|ccc|} 
& \multicolumn{3}{|c|}{ Mestrado } & \multicolumn{3}{c|}{ Doutorado } & \multicolumn{3}{c|}{ Geral } \\
& Filosofia & Schop. & $\%$ & Filosofia & Schop. & $\%$ & Filosofia & Schop. & $\%$ \\
\hline $\mathbf{2 0 1 3}$ & 477 & 10 & $2,10 \%$ & 128 & 2 & $1,56 \%$ & 605 & 12 & $1,98 \%$ \\
$\mathbf{2 0 1 4}$ & 477 & 11 & $2,31 \%$ & 140 & 0 & $0,00 \%$ & 617 & 11 & $1,78 \%$ \\
$\mathbf{2 0 1 5}$ & 511 & 13 & $2,54 \%$ & 183 & 5 & $2,73 \%$ & 694 & 18 & $2,59 \%$ \\
$\mathbf{2 0 1 6}$ & 461 & 9 & $1,95 \%$ & 161 & 0 & $0,00 \%$ & 622 & 9 & $1,45 \%$ \\
$\mathbf{2 0 1 7}$ & 566 & 8 & $1,41 \%$ & 228 & 5 & $2,19 \%$ & 794 & 13 & $1,64 \%$ \\
$\mathbf{2 0 1 8}$ & 489 & 7 & $1,43 \%$ & 221 & 3 & $1,36 \%$ & 710 & 10 & $1,41 \%$ \\
\hline Total & 2.981 & 58 & $1,95 \%$ & 1.061 & 15 & $1,41 \%$ & 4.042 & 73 & $1,81 \%$
\end{tabular}

Tabela 4: Representação da Pesquisa Schopenhauer na Pesquisa em Filosofia no Brasil (2013-2018). Fonte:

CTD/Capes e Painel de Informações Quantitativas/Capes. Elaboração do autor.

A tabela acima nos revela que, em um plano geral, a Pesquisa Schopenhauer produziu em média quase $2 \%$ das dissertações de mestrado do período e quase $1,5 \%$ das teses de doutorado. Isso significa que atualmente ela corresponde a cerca de 1,8\% da Pesquisa em Filosofia no Brasil. Também é possível notar que ela se encontra em uma leve tendência de decréscimo na representação. Nota-se, por exemplo, que a representação de Schopenhauer na produção global da Filosofia (considerando mestrados e doutorados) superava os 2,1\% no período de 2013 a 2015, mas cai para 1,5\% no período de 2016 a $2018 .{ }^{14}$

Em todo caso, dois fatores devem ser levados em consideração: (a) 1,5\% da produção de toda uma área de conhecimento não é um valor desprezível, o que permite declarar que Schopenhauer é hoje um autor muito importante na área de Filosofia, ainda que não seja o mais popular; (b) $\mathrm{O}$ recorte temporal que compõe a tabela acima é problemático, pois sua primeira metade (2013-2015) contempla o período de crescimento e ápice atípico das defesas sobre Schopenhauer, enquanto a segunda metade (2016-2018) contempla justamente todo o período de "queda" ou "volta à normalidade" das estatísticas schopenhauerianas. Como não chegamos a nenhuma explicação para o aumento súbito da produção sobre o filósofo, não conhecemos as razões de seu descaimento e tampouco sabemos se a tendência é de retorno ao ritmo de crescimento anterior das pesquisas ou de uma queda geral no interesse sobre os temas schopenhauerianos, os dados sobre a queda de representação de Schopenhauer devem ser declarados também como inconclusivos.

\section{Quais são os temas predominantes da Pesquisa Schopenhauer no Brasil?}

Uma grande dificuldade a ser superada em estudos como este é a de transformar as informações meramente quantitativas em conclusões qualitativas. As análises apresentadas nas seções anteriores deste artigo propõem alguns movimentos nesse sentido. Contudo, o material discutido até aqui não permite adentrar ao conteúdo das teses e dissertações analisadas. Para superar essa limitação, propus-me a envidar esforços no sentido de obter dados que permitissem uma análise das temáticas predominantes da Pesquisa Schopenhauer e, consequentemente, que permitissem uma identificação das tendências e características dessa Pesquisa ao longo do tempo.

Para a realização desse propósito, recorri à observação dos títulos dos trabalhos. Parto do pressuposto que o título de um trabalho de pós-graduação expressa, via de regra, de modo razoavelmente claro o tema principal do trabalho através de algumas palavras-chave que nele se encontram. Há, por certo, exceções a essa regra, mas tomo como pressuposto também que essas exceções não chegam a inviabilizar completamente uma análise

\footnotetext{
${ }^{14}$ Tal situação de queda de representação foi notada também no levantamento sobre a Pesquisa Nietzsche (MOREIRA, 2018).
} 
terminológica dos títulos dos trabalhos, sobretudo quando a amostra da pesquisa já é suficientemente ampla, como parece ser o caso presente.

Os títulos de todas as 354 teses e dissertações tomadas como objetos deste estudo, tanto sob a classificação de "primárias" quanto de "secundárias", possuem somadas quase 4000 palavras, das quais cerca de 1000 são palavras únicas e que serviram de base para as observações a seguir. Tendo em vista a dificuldade e talvez mesmo a inutilidade de se fazer uma análise de absolutamente todo e qualquer termo, optei por concentrar meus esforços apenas nas 20 palavras mais comuns nos títulos, sem considerar as palavras de estruturação dos títulos (artigos, conectivos, preposições etc.). As palavras "Arthur" e "Schopenhauer" usadas respectivamente 27 e 163 vezes nos títulos dos trabalhos "primários" - também não foram selecionadas para análise.

A partir da contagem das ocorrências e distribuição no tempo de cada um dos 20 termos mais comuns nos títulos das teses e dissertações, foram elaboradas as duas tabelas a seguir. A Tabela 5 apresenta a contagem e distribuição temporal das palavras constantes nos 181 trabalhos classificados como "primários". A Tabela 6 mostra a mesma organização de dados, porém com as palavras dos títulos de trabalhos classificados como "secundários". Ambas as tabelas estão organizadas de modo a mostrar a contagem de ocorrências de uma palavra de forma cumulativa (a exemplo do Gráfico 2).

\begin{tabular}{|c|c|c|c|c|c|c|c|c|c|c|c|c|c|c|c|c|c|c|c|c|c|c|c|c|c|c|c|c|c|c|}
\hline Termo & 1989 & 1990 & 1991 & 1992 & 1993 & 1994 & 1995 & 1996 & 1997 & 1998 & 1999 & 2000 & 2001 & 2002 & 2003 & 2004 & 2005 & 2006 & 2007 & 2008 & 2009 & 2010 & 2011 & 12012 & 2013 & 2014 & $\begin{array}{l}4015 \\
\end{array}$ & 52016 & 2017 & 2018 \\
\hline Filosofia & 0 & 0 & 0 & 0 & 0 & 0 & 0 & 1 & 1 & 1 & 2 & 2 & 3 & 4 & 5 & 5 & 7 & 8 & 9 & 12 & 15 & 22 & 24 & 24 & 28 & 30 & 34 & 34 & 36 & \\
\hline Vontade & 0 & 0 & 1 & 1 & 1 & 1 & 1 & 2 & 2 & 2 & 2 & 2 & 3 & 3 & 3 & 3 & 3 & 4 & 4 & 6 & 8 & 12 & 17 & 19 & 20 & 22 & 27 & 31 & 33 & 34 \\
\hline Metafísica & 0 & 0 & 1 & 1 & 1 & 1 & 1 & 1 & 1 & 1 & 1 & 1 & 2 & 2 & 2 & 3 & 3 & 4 & 4 & 4 & 6 & 11 & 11 & 13 & 14 & 15 & 18 & 21 & 23 & 24 \\
\hline Moral & 0 & 0 & 0 & 0 & 0 & 0 & 0 & 1 & 1 & 1 & 1 & 2 & 2 & 2 & 3 & 4 & 5 & 6 & 7 & 7 & 7 & 12 & 13 & 14 & 14 & 17 & 18 & 19 & 19 & 19 \\
\hline Ética & 0 & 0 & 0 & 0 & 0 & 0 & 0 & 0 & 0 & 0 & 1 & 1 & 1 & 1 & 1 & 2 & 3 & 4 & 7 & 7 & 7 & 7 & 9 & 10 & 10 & 11 & 14 & 16 & 18 & 18 \\
\hline Compaixão & 0 & 0 & 0 & 0 & 0 & 0 & 0 & 0 & 0 & 0 & 0 & 0 & 1 & 1 & 1 & 1 & 1 & 1 & 3 & 3 & 3 & 4 & 6 & 7 & 7 & 11 & 11 & 14 & 15 & 16 \\
\hline Nietzsche & 0 & 0 & 0 & 0 & 0 & 0 & 0 & 0 & 0 & 0 & 0 & 0 & 0 & 1 & 1 & 1 & 1 & 2 & 3 & 4 & 4 & 8 & 11 & 11 & 12 & 13 & 16 & 16 & 16 & 16 \\
\hline Conhecimento & 0 & 0 & 0 & 0 & 0 & 0 & 0 & 0 & 0 & 0 & 0 & 0 & 1 & 1 & 1 & 1 & 1 & 1 & 1 & 3 & 4 & 6 & 6 & 7 & 8 & 8 & 9 & 11 & 13 & 13 \\
\hline Estética & 0 & 0 & 0 & 0 & 0 & 0 & 0 & 0 & 0 & 0 & 0 & 1 & 1 & 1 & 1 & 1 & 1 & 3 & 3 & 3 & 4 & 5 & 5 & 8 & 9 & 9 & 11 & 11 & 12 & 12 \\
\hline Mundo & 0 & 0 & 0 & 0 & 0 & 0 & 0 & 0 & 0 & 0 & 0 & 0 & 0 & 0 & 1 & 1 & 2 & 3 & 3 & 3 & 3 & 5 & 7 & 8 & 9 & 9 & 10 & 10 & 11 & 12 \\
\hline Vida & 0 & 0 & 0 & 0 & 0 & 0 & 0 & 0 & 0 & 0 & 0 & 0 & 0 & 0 & 0 & 0 & 1 & 1 & 1 & 1 & 2 & 3 & 4 & 4 & 6 & 6 & 8 & 9 & 9 & 10 \\
\hline Crítica & 0 & 0 & 0 & 0 & 0 & 0 & 0 & 1 & 1 & 1 & 1 & 1 & 1 & 1 & 1 & 2 & 2 & 2 & 3 & 4 & 5 & 5 & 5 & 5 & 7 & 8 & 8 & 9 & 9 & 9 \\
\hline Pessimismo & 0 & 0 & 0 & 0 & 0 & 0 & 0 & 0 & 0 & 0 & 0 & 0 & 0 & 0 & 1 & 1 & 1 & 1 & 2 & 2 & 4 & 4 & 4 & 4 & 7 & 7 & 8 & 9 & 9 & 9 \\
\hline Razão & 0 & 0 & 0 & 0 & 0 & 0 & 0 & 0 & 0 & 0 & 0 & 0 & 0 & 0 & 0 & 0 & 0 & 0 & 0 & 3 & 3 & 5 & 5 & 5 & 6 & 6 & 6 & 7 & 8 & 9 \\
\hline Pensamento & 0 & 0 & 0 & 0 & 0 & 0 & 0 & 0 & 0 & 0 & 0 & 0 & 0 & 1 & 1 & 1 & 1 & 2 & 2 & 4 & 4 & 5 & 5 & 6 & 6 & 7 & 8 & 8 & 8 & 8 \\
\hline Representação & 0 & 0 & 0 & 0 & 0 & 0 & 0 & 0 & 0 & 0 & 0 & 0 & 0 & 0 & 0 & 0 & 0 & 0 & 0 & 0 & 0 & 0 & 2 & 2 & 4 & 4 & 6 & 7 & 7 & 8 \\
\hline Arte & 0 & 0 & 0 & 0 & 0 & 0 & 0 & 0 & 0 & 0 & 0 & 1 & 2 & 2 & 2 & 2 & 2 & 3 & 3 & 3 & 3 & 5 & 5 & 5 & 5 & 5 & 7 & 7 & 7 & 7 \\
\hline Belo & 0 & 0 & 0 & 0 & 0 & 0 & 1 & 1 & 1 & 1 & 1 & 1 & 1 & 1 & 1 & 1 & 1 & 2 & 2 & 2 & 3 & 4 & 4 & 4 & 4 & 4 & 4 & 6 & 7 & 7 \\
\hline Liberdade & 0 & 0 & 0 & 0 & 0 & 0 & 0 & 0 & 0 & 0 & 0 & 0 & 0 & 0 & 0 & 0 & 1 & 1 & 1 & 1 & 1 & 2 & 4 & 4 & 5 & 5 & 5 & 6 & 7 & 7 \\
\hline Música & 0 & 0 & 0 & 0 & 0 & 0 & 0 & 0 & 0 & 0 & 0 & 0 & 0 & 0 & 0 & 0 & 1 & 2 & 2 & 2 & 3 & 3 & 3 & 3 & 6 & 6 & 6 & 6 & 6 & 7 \\
\hline
\end{tabular}

Tabela 5: Distribuição cumulativa dos 20 termos mais comuns na Pesquisa Schopenhauer entre 1989 e 2018 (Trabalhos classificados como "primários"). Fonte: CTD/Capes. Elaboração do autor.

Ao analisar os dados da tabela acima, pode-se afirmar que alguns termos, em especial "filosofia”, "vontade”, “metafísica”, “mundo”, “crítica” e "pensamento" nos fornecem pouca ideia de que temas podem ser os mais explorados na Pesquisa Schopenhauer. Isso acontece porque são termos empregados em muitos contextos e temas diferentes na obra do próprio pensador. Porém, chama a atenção a presença bastante significativa de termos ligados em especial à temática ética ("moral", "ética”, “compaixão" e "liberdade”, com o total de 6o ocorrências). Portanto, tudo leva a crer que eles ocupem hoje uma posição de destaque na pesquisa sobre o filósofo alemão. Ao lado desses temas, também com algum destaque, é possível perceber os termos ligados à temática estética ("estética", "arte", "belo" e "música", com o total de 33 ocorrências). A metafísica da natureza não parece estar muito representada a não ser pela ideia mais genérica de estudo sobre a metafísica da vontade que, no entanto, é uma expressão poderia ser usada também para falar da ética ou da estética de Schopenhauer.

Os dados possibilitam percebem também que, falando de modo geral, os temas éticos foram significativamente mais explorados até aqui na Pesquisa Schopenhauer do que os 
126 | Schopenhauer no Brasil: Análise da presença schopenhaueriana em teses de doutorado e dissertações de mestrado de 1987 a 2018

temas estéticos. A julgar pela combinação dos termos "ética", "moral" e "compaixão", podemos supor que há uma tendência na Pesquisa Schopenhauer a tratar majoritariamente do princípio motriz da compaixão quando a temática do trabalho é predominantemente ética. Talvez soe mesmo natural a muitos(as) pesquisadores(as) que a compaixão deva ser o tema principal de trabalhos sobre a ética schopenhaueriana. No entanto, vale ressaltar que essa é opção teórica ao lado de outras opções válidas, como, por exemplo, eventuais análises e interpretações focadas nos conceitos de "egoísmo" e "crueldade", ou na problemática da relação entre temperamento e caráter, etc. Com efeito, esse exercício de pesquisa para além do problema da compaixão na ética schopenhaueriana tem sido realizado, por exemplo, pelas(os) pesquisadoras(es) da temática da liberdade. Os termos ligados a estética geram o mesmo questionamento. Para além de uma análise mais genérica a respeito da estética schopenhaueriana em geral, o tema específico mais explorado parece ser a metafísica da música do filósofo alemão.

Outro elemento importante de se observar na tabela é a presença do nome de um filósofo entre as ocorrências mais comuns. Trata-se de Nietzsche, cujo nome alcança a $6^{\mathbf{a}}$ posição entre os termos mais frequentes nos títulos da Pesquisa Schopenhauer, empatado com o termo "compaixão". Vale notar que a primeira ocorrência do nome é de 2002, mas a intensificação nos debates sobre ele acontece apenas a partir de 2006. Isso significa que atualmente se pode dizer que há uma tradição de debate ${ }^{15}$ da relação entre os dois filósofos que remonta a somente pouco mais de uma década em trabalhos de pós-graduação no Brasil, ainda que o número de trabalhos produzidos desde então não seja de modo algum desprezível.

Vale a pena agora deter-se também sobre a tabela temática dos trabalhos classificados como "secundários". Esses trabalhos foram classificados assim porque, na verdade, ainda que tivessem o termo "Schopenhauer" em seus resumos e eventualmente outros campos de registro do CTD/Capes, não trabalham senão perifericamente com o tema Schopenhauer. Porém, não é o caso de perder de vista que os autores desses trabalhos efetivamente inseriram o termo Schopenhauer entre seus dados. Uma análise de seus títulos pode indicar quais são os campos de aproximação e de contato entre a Pesquisa Schopenhauer e outros temas de pesquisa. Por essa razão, disponibilizo abaixo uma tabela com distribuição terminológica no período de 1989-2018 dos 20 termos mais comuns nos títulos das teses e dissertações classificadas como "secundárias":

\footnotetext{
${ }^{15}$ Quando menciono aqui a ideia de "tradição de debate" não ignoro que outros trabalhos sobre a relação dos dois filósofos já foram produzidos anteriormente, sobretudo na forma de artigos, livros, capítulos de livros, teses ou dissertações. Mesmo a amostra de teses e dissertações classificadas como "secundários" revela que a associação (mas não o debate) entre os nomes de Nietzsche e Schopenhauer está presente nos títulos ou resumos dos trabalhos de pós-graduação desde 1995 (cf. Tabela 6). O que quero dizer é que há pouco mais de uma década instaura-se uma tradição específica nos trabalhos de pós-graduação brasileira, uma tradição que mais do que fazer a relação entre Nietzsche e Schopenhauer em vistas de uma análise outra, dispõe o confronto entre ambos os filósofos como objeto central do próprio trabalho.
} 


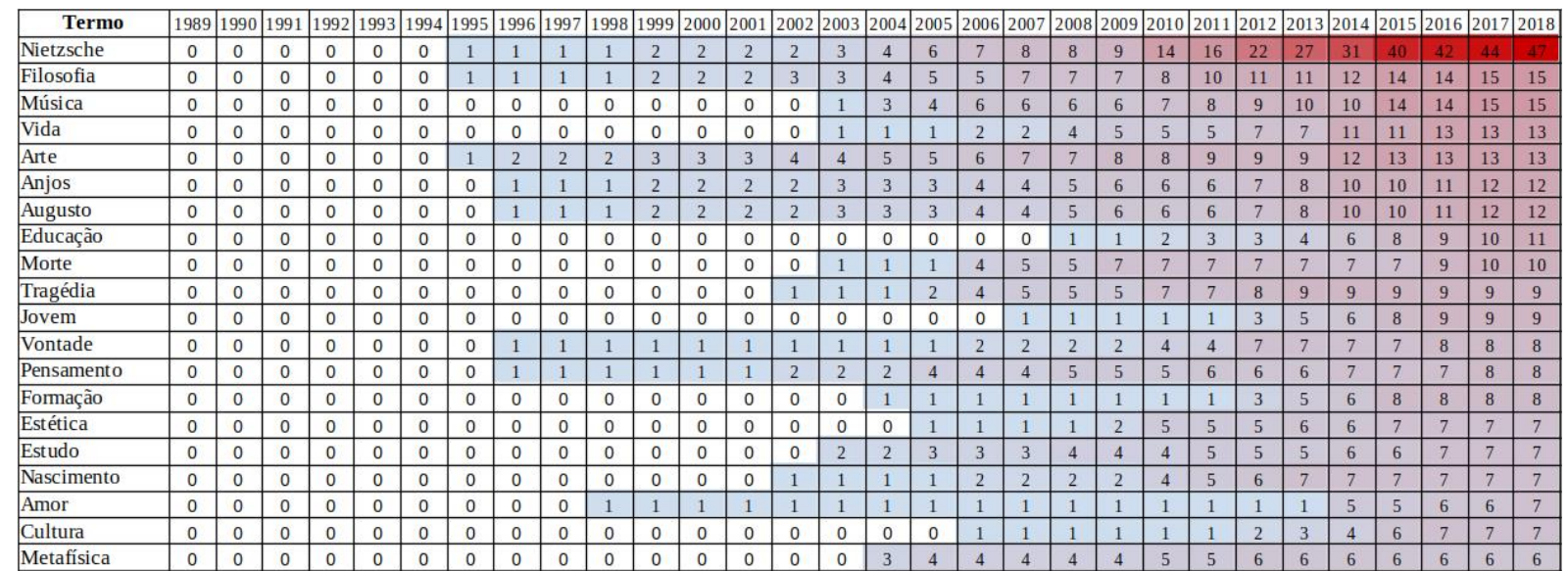

Tabela 6: Distribuição cumulativa dos 20 termos mais comuns na Pesquisa Schopenhauer entre 1989 e 2018 (Trabalhos classificados como "secundários"). Fonte: CTD/Capes. Elaboração do autor.

Depara-se aqui com um retorno de Nietzsche, porém agora ocupando a $1^{-a}$ posição entre os termos mais comuns. Trata-se em geral de trabalhos sobre Nietzsche que mencionam, por um motivo ou outro, Schopenhauer ou à obra Schopenhauer como educador em seus resumos. Ao mesmo tempo, percebe-se na tabela acima que o tema da estética agora tem muito mais destaque por meio de termos como "música", "arte", "tragédia" e "estética". Especialmente "música" e "tragédia" nos fazem lembrar em especial da obra $O$ nascimento da tragédia, de Nietzsche. Reforçam essa ideia os termos "jovem", "cultura”, "nascimento". Também podem ser lidos dentro da esfera de influência nietzschiana os termos "educação" e "formação".

A contagem terminológica não pode verdadeiramente definir por si só qual é a conexão entre os termos de busca mais comuns. Porém, ao proceder a análise manual da ocorrência de cada termo de busca, confirma-se que se tratam de termos ligados, em sua maioria, a estudos sobre o pensamento de Nietzsche, principalmente em torno dos temas apresentados em $O$ nascimento da tragédia e Schopenhauer como educador. Mas, diferente dos estudos que foram classificados como "primários", nesses trabalhos "secundários" não se evidencia o intuito de promover uma análise conjunta dos pensamentos nietzschiano e schopenhaueriano.

Os termos "amor", "morte”, "Anjos" e "Augusto, por sua vez, estão ligados ao contexto de pesquisa sobre literatura, em especial literatura brasileira. Se torna evidente, graças à ocorrência desses termos e a análise manual posterior, que os trabalhos em PPGs da área de Letra, que aqui foram classificados como "secundários", apesar de serem muitíssimo variados entre si, costumam remeter-se ao filósofo da vontade de vida em seus resumos em razão de algum elo entre ele o tema ou literato(a) que se pretende efetivamente estudar. Entre os(as) muitos(as) escritores(as) mencionadas, destaca-se de fato o poeta brasileiro Augusto dos Anjos.

Tais conexões frequentes de Schopenhauer em estudos sobre outros(as) pensadores(as), assim como as conexões frequentes de outros(as) pensador(as) nos estudos sobre Schopenhauer evidencia o quão relacional têm sido a Pesquisa Schopenhauer no Brasil. Considerando novamente apenas as teses e dissertações classificadas como "primárias", percebe-se que, embora apenas o nome de Nietzsche apareça entre os 20 termos mais comuns, 21 pessoas são mencionadas ao todo nos títulos dos trabalhos defendidos: ${ }^{16}$ Nietzsche (16 menções); Freud (6 menções); Kant (8); Wagner (4); Machado de Assis (3); Goethe (2); Horkheimer (2); Baudelaire (2); Platão (2); Schelling (2); Augusto dos Anjos (1);

${ }^{16}$ Considera-se aqui uma menção tanto o emprego do nome próprio da pessoa, quanto a versão adjetivada dele. 
128 | Schopenhauer no Brasil: Análise da presença schopenhaueriana em teses de doutorado e dissertações de mestrado de 1987 a 2018

Kafka (1); Camilo Pessanha (1); Cruz e Sousa (1); Eça de Queiroz (1); Huysmans (1); Hegel (1); Humboldt (1); Lutero (1); Marx (1); e Jailson Marcos (1). Em outras palavras, das 181 teses e dissertações selecionadas, 50 se propõem em seus títulos a fazer um trabalho relacional $(27,62 \%)$.

Entretanto, essa informação possui um significado duplo. Por um lado, torna visível o potencial do pensamento schopenhaueriano para a promoção de debates filosóficos, inclusive com pensadores(as) e artistas menos óbvios. Por outro lado, evidenciam também o quanto certos temas e conexões foram ainda pouco exploradas. O exemplo para isso que mais me chama atenção é o de Platão e Goethe. Ambos são referências teóricas importantes para o filósofo de Frankfurt, das quais muitos e ricos estudos poderiam já ter surgido, porém parecem ter sido colocados ambos em segundo plano. Outro exemplo semelhante poderia ser encontrado, por exemplo, em personalidades que sequer aparecem na lista acima, tais como Agostinho de Hipona e Meister Eckhart.

\section{Considerações finais}

Traçar e mapear a história das pesquisas sobre o pensamento de um filósofo não é uma tarefa fácil. Dentre a multiplicidade de abordagens possíveis, uma investigação quantitativa é certamente muito pouco comum na área de Filosofia. É verdade que toda investigação desse tipo é cercada de limites e limitações e de modo nenhum deve ser considerada suficiente para a compreensão completa das trajetórias que as diversas filosofias traçam no Brasil. No entanto, penso que os resultados do presente estudo evidenciam de modo suficientemente claro que esse tipo de abordagem também possui suas vantagens. Uma investigação como a que se apresenta neste artigo nos permite, por exemplo, alcançar uma visão ampla sobre o objeto de estudo, de modo que é possível pintar um quadro geral do estado da arte das pesquisas sobre um(a) autor(a) determinado(a). De posse de tal quadro, é possível identificar potencialidades e também arriscar algumas previsões sobre os rumos futuros de um campo de pesquisa.

Neste estudo, cada uma das quatro perguntas básicas que orientaram os esforços de pesquisa apresentou esse duplo resultado: percepção da condição atual e leitura de possibilidades e expectativas para o futuro da Pesquisa Schopenhauer na pós-graduação brasileira. Os resultados podem ser resumidos da seguinte forma:

Quanto à pergunta 1: Geograficamente, a Pesquisa Schopenhauer se concentra tradicionalmente nas Regiões Sul, Nordeste e, especialmente na Região Sudeste (cf. Tabela 1). O estado de São Paulo é o mais produtivo (cf. Gráfico 1) praticamente por todo o período registrado no Catálogo de Teses e Dissertações da Capes (1987-2018). A expectativa é que o Sudeste permaneça caracterizado como a região mais produtiva, mas a produtividade recente e ascendente de universidades no Sul e no Nordeste devem modificar nos próximos anos os percentuais de produção de cada região sensivelmente.

Quanto à pergunta 2: Constatou-se aqui que, como esperado, há mais estudos sobre o filósofo alemão na forma de dissertações de mestrado do que em teses de doutorado. No entanto, a presença de Schopenhauer em trabalhos de doutoramento é bastante elevada. Além disso, a dinâmica de produção ao longo do tempo até aqui apresentada, cria a expectativa de que o número de teses de doutorado defendidas nos próximos anos continue razoavelmente alto ou mesmo se eleve ainda mais, caso fatores externos não comprometam a produtividade da pós-graduação brasileira nesse período.

Quanto à pergunta 3: Quase 18\% da Pesquisa Schopenhauer não acontece em PPGs da área de Filosofia. A maior parte das pesquisas dessas outras áreas ocorreram em PPGs de 
outras ciências humanas ou sociais aplicadas. No entanto, não se pode afirmar que algum desses programas e áreas tenha de fato consolidado a Pesquisa Schopenhauer em seu interior. As produções são esparsas no tempo e difundidas no espaço. Não encontrei indícios de que essa situação mude no futuro próximo, a não ser que as(os) atuais pesquisadoras(es) do filósofo alemão fortaleçam os esforços de promoção de laços e estudos entre o pensamento schopenhaueriano e as mais diversas áreas de saber. ${ }^{17} \mathrm{Ou}$ seja, há muitos espaços de pesquisa pouco explorados.

Quanto à pergunta 4: A busca por temas predominantes permitiu que se chegue à compreensão de que o tema da moralidade, principalmente no tocante ao conceito de compaixão, encontra-se hoje com maior número de pesquisas do que outros temas clássicos do pensamento schopenhaueriano, como a estética. Além disso, assim como as pesquisas sobre a ética schopenhaueriana tendem a se concentrar no conceito de compaixão, as pesquisas sobre a estética tendem a uma tematização ampla da estética como um todo ou a uma tematização específica da música. Foi também através da análise terminológica que se chegou a uma lista de autores, com os quais a Pesquisa Schopenhauer tem buscado estabelecer elos; entre eles os maiores destaques são Nietzsche, Kant e Freud. Isso permitiu que fosse aventada a hipótese de que a Pesquisa Schopenhauer teria uma forte tendência a produzir estudos relacionais. Não obstante, é importante perceber que há espaço para desenvolver muitos outros trabalhos com pensadoras(es) ou artistas pouco explorados ou ignorados.

\section{Referências}

CACCIOLA; SALVIANO; DEBONA. Geschichte und aktuelle Situation der SchopenhauerStudien in Brasilien. Schopenhauer-Jahrbuch, v. 96, 2015, pp. 155-160.

FREZZATTI JR., Wilson. A recepção de Nietzsche na França: da Revue philosophique de la France et de l'Étranger ao período entreguerras. Cadernos Nietzsche, São Paulo, n. 30, 2012.

CAPES. Catálogo de Teses e Dissertações. Disponível em

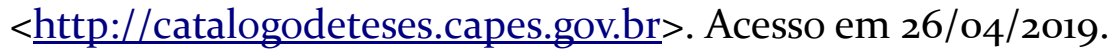

CAPES. Painel de Informações Quantitativas (Teses e Dissertações). Disponível em $<$ http://analisevisual.capes.gov.br/SASVisualAnalyticsViewer/VisualAnalyticsViewer guest.js p?reportName $=$ Banco+de+Teses+e+Disserta $\% \mathrm{C}_{3} \% \mathrm{~A}_{7} \% \mathrm{C}_{3} \% \mathrm{~B}_{5} \mathrm{es}+-$

+ Informa $\% \mathrm{C}_{3} \% \mathrm{~A}_{7} \% \mathrm{C}_{3} \% \mathrm{~B}_{5}$ es+quantitativas\&reportPath=/DTI/Banco de teses e dissertaco es/Relatorios\&reportViewOnly=false\&appSwitcherDisabled=true >. Acesso em 26/04/2019.

CAPES. Plataforma Sucupira. Disponível em <https://sucupira.capes.gov.br/sucupira/> Acesso em 30/04/2019.

SÁ MOREIRA, Fernando de. A Pesquisa Nietzsche no Brasil: análise quantitativa de teses e dissertações entre 2010 e 2018. Estudos Nietzsche, v. 9, n. 1, jan./jun. 2018, pp. 120-133.

17 Em verdade, o próprio Schopenhauer fez esse esforço continuamente em sua trajetória intelectual, como evidenciam diversas passagens em sua obra e, principalmente, o livro Sobre a vontade na natureza. 
130 | Schopenhauer no Brasil: Análise da presença schopenhaueriana em teses de doutorado e dissertações de mestrado de 1987 a 2018

SÁNCHEZ, Sergio. Nietzsche no Rio da Prata. Cadernos Nietzsche, São Paulo, n. 33, 2013.

SCHOPENHAUER, Arthur. Sobre la voluntad en la naturaleza. Tradução de M. de Unamuno.

Buenos Aires: Siglo Veinte, 1947.

SCHOPENHAUER, Arthur. Zürcher Ausgabe: Werke in zehn Bänden. Zürich: Diogenes, 1977.

\section{Anexo I - Referências das Teses e Dissertações classificadas como "primárias"}

1. RODRIGUES, Victor Hugo Guimarães. Platão e Schopenhauer: Artistas diante do Espelho. Dissertação de Mestrado defendida no Programa de Pós-Graduação em Filosofia da Universidade Federal de Santa Maria. Santa Maria-RS, 1989.

2. CACCIOLA, Maria Lúcia Mello e Oliveira. Schopenhauer e a Questão do Dogmatismo. Tese de Doutorado defendida no Programa de Pós-Graduação em Filosofia da Universidade de São Paulo. São Paulo-SP, 1990.

3. JARDIM, Candeloro Rosana. Machado de Assis e Schopenhauer: Uma "Metafísica da Vontade. Dissertação de Mestrado defendida no Programa de Pós-Graduação em Letras da Universidade Federal do Rio Grande do Sul. Porto Alegre-RS, 1991.

4. $\quad$ BARBOZA, Jair Lopes. "A Metafísica do Belo de Arthur Schopenhauer". Dissertação de Mestrado defendida no Programa de Pós-Graduação em Filosofia da Universidade de São Paulo. São Paulo-SP, 1995.

5. MOREIRA, Jacqueline de Oliveira. A Negação da Vontade: O Problema da Fundamentação da Moral na Filosofia do Schopenhauer. Dissertação de Mestrado defendida no Programa de Pós-Graduação em Filosofia da Universidade Federal de Minas Gerais. Belo Horizonte-MG, 1996.

6. LOPES, Christine Mello de Mattos. Crítica de Schopenhauer a Kant. Dissertação de Mestrado defendida no Programa de Pós-Graduação em Filosofia da Universidade Federal do Rio de Janeiro. Rio de Janeiro-RJ, 1996.

7. RODRIGUES, Eli Vagner Francisco. Ética e Teleologia na Filosofia de Schopenhauer. Dissertação de Mestrado defendida no Programa de Pós-Graduação em Filosofia da Universidade Estadual de Campinas. Campinas-SP, 1999.

8. MESQUITA, Zoraide Rodrigues Carrasco de. "A Insigne Dor Humana (Presença de Schopenhauer na Poesia de Camilo Pessanha)". Dissertação de Mestrado defendida no Programa de Pós-Graduação em Letras (Literatura Portuguesa) da Universidade de São Paulo. São Paulo-SP, 2000.

9. $\quad$ FREITAS, Onofre de. Eça, Huysmans e Schopenhauer - Uma Ironia da "Decadência". Tese de Doutorado defendida no Programa de Pós-Graduação em Estudos Literários da Universidade Federal de Minas Gerais. Belo Horizonte-MG, 2000.

10. BARBOSA, Jair Lopes. Infinitude Subjetiva e Estética: A Recepção e Assimilação dos Conceitos de Natureza e Arte de Schelling em Schopenhauer. Tese de Doutorado defendida no Programa de Pós-Graduação em Filosofia da Universidade de São Paulo. São Paulo-SP, 2000.

11. JÚNIOR, Renato Nogueira dos Santos. O Fundamento da Moral: Schopenhauer Crítico de Kant. Dissertação de Mestrado defendida no Programa de Pós-Graduação em Filosofia da Universidade Federal de São Carlos. São Carlos-SP, 2000.

12. NETO, Henrique Duarte. As Cosmovisões Pessimistas de Schopenhauer e Augusto dos Anjos. Dissertação de Mestrado defendida no Programa de Pós-Graduação em Literatura da Universidade Federal de Santa Catarina. Florianópolis-SC, 2000. 
13. GONÇALVES, Rosa Gabriella de Castro. Arte e Metafísica na Filosofia de Schopenhauer. Dissertação de Mestrado defendida no Programa de Pós-Graduação em Filosofia da Universidade de São Paulo. São PauloSP, 2001.

14. SALVIANO, Jarlee Oliveira Silva. Niilismo de Schopenhauer. Dissertação de Mestrado defendida no Programa de Pós-Graduação em Filosofia da Universidade de São Paulo. São Paulo-SP, 2001.

15. ALMEIDA, Rejane Souza de. Vontade e Conhecimento Filosófico em Arthur Schopenhauer. Dissertação de Mestrado defendida no Programa de Pós-Graduação em Filosofia da Universidade Federal de Pernambuco. Recife-PE, 2001.

16. SANTOS, Mauro Leonardo Salvador Caldeira dos. A Compaixão e suas Vicissitudes na Prática da Enfermagem. Tese de Doutorado defendida no Programa de Pós-Graduação em Enfermagem da Universidade Federal de Santa Catarina. Florianópolis-SC, 2001.

17. MORAES, Jorge Chaves de. O Pensamento Dissonante: Schopenhauer, Wagner, Nietzsche e o Nascimento da Filosofia Musical. Dissertação de Mestrado defendida no Programa de Pós-Graduação em Filosofia da Universidade Federal do Rio de Janeiro. Rio de Janeiro-RJ, 2002.

18. NORONHA, Viviane de Lamare. Schopenhauer e Machado - Encontros e Desencontros. Tese de Doutorado defendida no Programa de Pós-Graduação em Letras da Universidade do Estado do Rio de Janeiro. Rio de Janeiro-RJ, 2003.

19. FONSECA, Eduardo Ribeiro da. Corpo e Mundo em Schopenhauer e Freud. Dissertação de Mestrado defendida no Programa de Pós-Graduação em Filosofia da Universidade Federal do Paraná. Curitiba-PR, 2003.

20. PAULA, Robespierre Alconfor M de. Do Otimismo Marxista ao Pessimismo Schopenhaueriano em Horkheimer. Dissertação de Mestrado defendida no Programa de Pós-Graduação em Filosofia da Universidade Federal de Goiás. Goiânia-GO, 2003.

21. ROCHA, Fábio Libório. O Conceito de Servo Arbítrio em Schopenhauer. Dissertação de Mestrado defendida no Programa de Pós-Graduação em Filosofia da Universidade Gama Filho. Rio de Janeiro-RJ, 2003.

22. RAMOS, Flamarion Caldeira. Tragédia e Redenção: O Significado Moral da Existência na Filosofia de Schopenhauer. Dissertação de Mestrado defendida no Programa de Pós-Graduação em Filosofia da Universidade de São Paulo. São Paulo-SP, 2003.

23. BRANDÃO, Eduardo. O Conceito de Matéria na Obra de Schopenhauer. Tese de Doutorado defendida no Programa de Pós-Graduação em Filosofia da Universidade de São Paulo. São Paulo-SP, 2003.

24. STAUDT, Leo Afonso. O Significado Moral das Ações Humanas: Metafísica e Ética em Arthur Schopenhauer. Tese de Doutorado defendida no Programa de Pós-Graduação em Filosofia da Pontifícia Universidade Católica do Rio Grande do Sul. Porto Alegre-RS, 2004.

25. JUNIOR, Dermeval de Sena Aires. Sobre a Atualidade de Schopenhauer: Uma Meditação Crítica, uma Experiência Transcendente. Dissertação de Mestrado defendida no Programa de Pós-Graduação em Engenharia de Produção da Universidade Federal do Rio de Janeiro. Rio de Janeiro-RJ, 2004.

26. SILVA, Rejane Valvano Correa da. A Responsabilidade no Sistema Filosófico de Schopenhauer. Dissertação de Mestrado defendida no Programa de Pós-Graduação em Filosofia da Pontifícia Universidade Católica do Rio de Janeiro. Rio de Janeiro-RJ, 2004.

27. CHEVITARESE, Leandro Pinheiro. A Ética em Schopenhauer: Que "Liberdade nos Resta para a Prática de Vida? Tese de Doutorado defendida no Programa de Pós-Graduação em Filosofia da Pontifícia Universidade Católica do Rio de Janeiro. Rio de Janeiro-RJ, 2005.

28. BASSOLI, Selma Aparecida. O Conceito de Grandeza Negativa na Filosofia Moral de Schopenhauer. Dissertação de Mestrado defendida no Programa de Pós-Graduação em Filosofia da Universidade Estadual de Campinas. Campinas-SP, 2005. 
132 | Schopenhauer no Brasil: Análise da presença schopenhaueriana em teses de doutorado e dissertações de mestrado de 1987 a 2018

29. MARTON, Silmara Lidia. Música, Filosofia, Formação: por uma Escola Sensível do Mundo. Dissertação de Mestrado defendida no Programa de Pós-Graduação em Educação da Universidade Federal do Rio Grande do Norte. Natal-RN, 2005 .

30. JUNIOR, Renato Nogueira Dos Santos. O Mundo como Espetáculo Estético: A Metafísica do Belo de Schopenhauer. Tese de Doutorado defendida no Programa de Pós-Graduação em Filosofia da Universidade Federal do Rio de Janeiro. Rio de Janeiro-RJ, 2006.

31. MORAES, Jorge Chaves de. A Estética do Caos: Schelling, Schopenhauer e Nietzsche. Tese de Doutorado defendida no Programa de Pós-Graduação em Filosofia da Universidade Federal do Rio de Janeiro. Rio de Janeiro-RJ, 2006.

32. VIEIRA, Franciele Krindges. O Vínculo entre a Música e a Vontade na Filosofia de Arthur Schopenhauer. Dissertação de Mestrado defendida no Programa de Pós-Graduação em Filosofia da Universidade Federal do Paraná. Curitiba-PR, 2006.

33. MARTINS, Eduardo de Carvalho. Freud e Schopenhauer: Os Limites de um Diálogo sobre a Moral. Dissertação de Mestrado defendida no Programa de Pós-Graduação em Filosofia da Universidade Federal de São Carlos. São Carlos-SP, 2006.

34. COVIELLO, João. O Vínculo entre Ética e Estética no Pensamento de Schopenhauer com um Olhar Especial sobre a Arte Contemporânea. Dissertação de Mestrado defendida no Programa de Pós-Graduação em Filosofia da Pontifícia Universidade Católica do Paraná. Curitiba-PR, 2006.

35. GUIMARÃES, Maria das Graças Matos Côrtes. A Filosofia Moral de Schopenhauer. Dissertação de Mestrado defendida no Programa de Pós-Graduação em Filosofia da Universidade Federal do Rio de Janeiro. Rio de Janeiro-RJ, 2007.

36. JUNIOR, Jamil Salloum. A Ética Ascética de Arthur Schopenhauer e o Hinduísmo um Estudo BibliográficoComparativo: Assonâncias e Dissonâncias. Dissertação de Mestrado defendida no Programa de PósGraduação em Filosofia da Pontifícia Universidade Católica do Paraná. Curitiba-PR, 2007.

37. ALMEIDA, Patrícia Sheyla Bagot de. "O Pessimismo Schopenhaueriano na Obra Chove nos Campos de Cachoeira". Dissertação de Mestrado defendida no Programa de Pós-Graduação em Letras: Lingüística e Teoria Literária da Universidade Federal do Pará. Belém-PA, 2007.

38. MESQUITA, Fábio Luiz de Almeida. Schopenhauer e o Oriente. Dissertação de Mestrado defendida no Programa de Pós-Graduação em Filosofia da Universidade de São Paulo. São Paulo-SP, 2007.

39. SAlVIANO, Jarlee Oliveira Silva. Labirintos do Nada: A Crítica de Nietzsche ao Niilismo de Schopenhauer. Tese de Doutorado defendida no Programa de Pós-Graduação em Filosofia da Universidade de São Paulo. São Paulo-SP, 2007.

40. FERREIRA, Fábio Lustosa. A Ética da Compaixão de Schopenhauer em sua Intersecção com a Ética da Compaixão Budista. Dissertação de Mestrado defendida no Programa de Pós-Graduação em Filosofia da Pontifícia Universidade Católica do Paraná. Curitiba-PR, 2007.

41. CARDOSO, Renato César. A Idéia de Justiça em Schopenhauer. Tese de Doutorado defendida no Programa de Pós-Graduação em Direito da Universidade Federal de Minas Gerais. Belo Horizonte-MG, 2008.

42. PEREIRA, Marcelo Marques. O Conhecimento Humano como Expressão da Vontade: Análise das Relações entre o Conhecimento Abstrato e o Intuitivo no Pensamento de Schopenhauer. Dissertação de Mestrado defendida no Programa de Pós-Graduação em Filosofia da Pontifícia Universidade Católica do Rio de Janeiro. Rio de Janeiro-RJ, 2008.

43. PETRICH, Lademir Renato. A Resignação como Processo Libertador da Vontade na Filosofia de Arthur Schopenhauer. Dissertação de Mestrado defendida no Programa de Pós-Graduação em Ciência da Religião da Universidade Federal de Juiz de Fora. Juiz de Fora-MG, 2008. 
44. XAVIER, Anderson da Costa. Machado de Assis e Arthur Schopenhauer: Literatura e Filosofia em Quincas Borba. Dissertação de Mestrado defendida no Programa de Pós-Graduação em Letras (Letras Vernáculas) da Universidade Federal do Rio de Janeiro. Rio de Janeiro-RJ, 2008.

45. DEBONA, Vilmar. As Formas da Razão no Pensamento de Schopenhauer e a Possibilidade de uma Razão Ético-Mística. Dissertação de Mestrado defendida no Programa de Pós-Graduação em Filosofia da Pontifícia Universidade Católica do Paraná. Curitiba-PR, 2008.

46. RODRIGUES, Eli Vagner Francisco. A Caracterização Niilista da Filosofia de Schopenhauer a Partir da Crítica de Nietzsche. Tese de Doutorado defendida no Programa de Pós-Graduação em Filosofia da Universidade Estadual de Campinas. Campinas-SP, 2008.

47. JUNIOR, William Massei. Os Limites da Razão em Luther e Schopenhauer. Dissertação de Mestrado defendida no Programa de Pós-Graduação em Filosofia da Universidade Estadual de Campinas. CampinasSP, 2008.

48. RAMOS, Flamarion Caldeira. A "Miragem" do Absoluto: Sobre a Contraposição de Schopenhauer a Hegel: Crítica, Especulação e Filosofia da Religião. Tese de Doutorado defendida no Programa de Pós-Graduação em Filosofia da Universidade de São Paulo. São Paulo-SP, 2009.

49. SOUSA, James Wagner Alves de. Schopenhauer: do Pessimismo Metafísico ao Otimismo Prático. Dissertação de Mestrado defendida no Programa de Pós-Graduação em Filosofia da Universidade Federal da Paraíba. João Pessoa-PB, 2009.

50. BARRETO, Cassio de Barros. O Papel da Intuição Estética na Teoria do Conhecimento Schopenhaueriana. Dissertação de Mestrado defendida no Programa de Pós-Graduação em Filosofia da Universidade do Estado do Rio de Janeiro. Rio de Janeiro-RJ, 2009.

51. TEODORO, Jefferson Silveira. A Origem da Santidade segundo a Metafísica de Schopenhauer. Dissertação de Mestrado defendida no Programa de Pós-Graduação em Ciência da Religião da Universidade Federal de Juiz de Fora. Juiz de Fora-MG, 2009.

52. JUNIOR, Helio Dias da Costa. Pessimismo e Afirmação da Vontade de Vida de Schopenhauer. Dissertação de Mestrado defendida no Programa de Pós-Graduação em Filosofia da Universidade Federal de Minas Gerais. Belo Horizonte-MG, 2009.

53. BRAND, Jorge Gomes de Oliveira. Schopenhauer e o Coração da Natureza. Dissertação de Mestrado defendida no Programa de Pós-Graduação em Filosofia da Universidade Federal do Paraná. Curitiba-PR, 2009.

54. TELES, Alexandre. O Sistema de Filosofia Transcendental de Schopenhauer: Uma Interpretação e Defesa. Dissertação de Mestrado defendida no Programa de Pós-Graduação em Filosofia da Universidade Federal do Rio Grande do Sul. Porto Alegre-RS, 2009.

55. QUIRINO, Marcio Paiva. Sobre a Metafísica do Belo de Arthur Schopenhauer. Dissertação de Mestrado defendida no Programa de Pós-Graduação em Filosofia da Universidade Federal da Paraíba. João Pessoa-PB, 2009 .

56. NOCKO, Caio Manoel. A Complexidade da Música na Filosofia de Arthur Schopenhauer. Dissertação de Mestrado defendida no Programa de Pós-Graduação em Música da Universidade Federal do Paraná. Curitiba-PR, 2009.

57. FETALIAN, Tiago. A Questão da Negação da Vontade em Schopenhauer especialmente no IV Livro do M.V.R. Dissertação de Mestrado defendida no Programa de Pós-Graduação em Filosofia da Universidade do Vale do Rio dos Sinos. São Leopoldo-RS, 2009.

58. ROCHAMONTE, Catarina. Metafísica e Moralidade na Filosofia de Schopenhauer. Dissertação de Mestrado defendida no Programa de Pós-Graduação em Filosofia da Universidade Federal do Rio Grande do Norte. Natal-RN, 2010. 
134 | Schopenhauer no Brasil: Análise da presença schopenhaueriana em teses de doutorado e dissertações de mestrado de 1987 a 2018

59. JÚNIOR, René Armand Dentz. Idéia, Vontade e Arte em Schopenhauer. Tese de Doutorado defendida no Programa de Pós-Graduação em Filosofia da Pontifícia Universidade Católica de São Paulo. São Paulo-SP, 2010.

6o. MASSIGNANI, Antonio Carlos. A Questão da Redenção: Uma Aproximação entre Schopenhauer e Nietzsche. Dissertação de Mestrado defendida no Programa de Pós-Graduação em Filosofia da Pontifícia Universidade Católica do Paraná. Curitiba-PR, 2010.

61. PEREIRA, Bruno Braga. Desvelamento do Mundo: O Fundamento da Moral para além dos Limites da Razão na Filosofia de Schopenhauer. Dissertação de Mestrado defendida no Programa de Pós-Graduação em Filosofia da Universidade Federal de Minas Gerais. Belo Horizonte-MG, 2010.

62. FUCHS, Paulo Roberto. Metafísica e Corpo em Schopenhauer. Dissertação de Mestrado defendida no Programa de Pós-Graduação em Filosofia da Pontifícia Universidade Católica do Paraná. Curitiba-PR, 2010.

63. LIMA, Maria Socorro de. Vontade e Conhecimento como Fundamento para a Moral em Schopenhauer. Dissertação de Mestrado defendida no Programa de Pós-Graduação em Filosofia da Universidade Estadual do Oeste do Paraná. Toledo-PR, 2010.

64. ESPÍNDOLA, Camila Koerich. A Consideração Moral Não-Antropocêntrica na Filosofia de Arthur Schopenhauer. Dissertação de Mestrado defendida no Programa de Pós-Graduação em Filosofia da Universidade Federal de Santa Catarina. Florianópolis-SC, 2010.

65. FERREIRA, Marcos Eduardo Leite. A Relação entre Idéias e Arte com um Olhar sobre o Conflito do Mundo na Estética de Schopenhauer. Dissertação de Mestrado defendida no Programa de Pós-Graduação em Estética e Filosofia da Arte da Universidade Federal de Ouro Preto. Ouro Preto-MG, 2010.

66. SANTOS, Kátia Cilene da Silva. O Problema da Liberdade na Filosofia de Arthur Schopenhauer. Dissertação de Mestrado defendida no Programa de Pós-Graduação em Filosofia da Universidade de São Paulo. São Paulo-SP, 2010.

67. FONSECA, Eduardo Ribeiro da. Psiquismo e Vida - O Conceito de Impulso em Freud, Schopenhauer e Nietzsche. Tese de Doutorado defendida no Programa de Pós-Graduação em Filosofia da Universidade de São Paulo. São Paulo-SP, 2010.

68. GERMER, Guilherme Marconi. O Belo e o Bom em Schopenhauer. Dissertação de Mestrado defendida no Programa de Pós-Graduação em Filosofia da Universidade Estadual de Campinas. Campinas-SP, 2010.

69. EUCLIDES, Raul Moraes de. A Filosofia da Vontade e as Interpretações da Tragédia: Uma Análise das Teorias de Schopenhauer e do Jovem Nietzsche. Dissertação de Mestrado defendida no Programa de Pós-Graduação em Estética e Filosofia da Arte da Universidade Federal de Ouro Preto. Ouro Preto-MG, 2010.

70. ROMEIRO, Artieres Estevão. Schopenhauer e a Metafísica da Vontade: Confluências Éticas e Estéticas para uma Abordagem da Educação e da Sexualidade. Dissertação de Mestrado defendida no Programa de PósGraduação em Educação da Universidade Estadual de Campinas. Campinas-SP, 2010.

71. GUTIERREZ, Leandro Cardoso. O Fundamento da Moral no Pensamento de Arthur Schopenhauer. Dissertação de Mestrado defendida no Programa de Pós-Graduação em Filosofia da Universidade São Judas Tadeu. São Paulo-SP, 2010.

72. PEDREIRA, André Luiz Simões. Educação e Metafísica em Schopenhauer. Dissertação de Mestrado defendida no Programa de Pós-Graduação em Educação da Universidade Federal da Bahia. Salvador-BA, 2010 .

73. SILVA, Edward Flaviano da. Nietzsche e a Moral da Compaixão: Identificação e Superação do Princípio Ascético-Compassivo Schopenhaueriano. Dissertação de Mestrado defendida no Programa de PósGraduação em Ciências da Religião da Pontifícia Universidade Católica de Minas Gerais. Belo HorizonteMG, 2010. 
74. SOARES, Daniel Quaresma Figueira. A Função do Corpo na Filosofia de Schopenhauer - Conhecimento, Metafísica e o Problema da Coisa em Si. Dissertação de Mestrado defendida no Programa de Pós-Graduação em Filosofia da Universidade de São Paulo. São Paulo-SP, 2010.

75. SILVA, Paulo Marcos da. O Princípio de Razão Suficiente (1813) e a Questão da Verdade em Schopenhauer. Dissertação de Mestrado defendida no Programa de Pós-Graduação em Filosofia da Universidade de São Paulo. São Paulo-SP, 2010.

76. KLEIN, Fernando. A Anatomia da Felicidade em Cruz e Sousa (1861-1898) - entre a Filosofia de Schopenhauer (1788-1860) e a Poesia de Baudelaire (1821-1867). Dissertação de Mestrado defendida no Programa de PósGraduação em Letras da Universidade Estadual de Maringá. Maringá-PR, 2010.

77. LIMA, Felipe Cardoso Martins. O Desafio da Liberdade na Filosofia de Schopenhauer. Dissertação de Mestrado defendida no Programa de Pós-Graduação em Filosofia da Pontifícia Universidade Católica do Paraná. Curitiba-PR, 2011.

78. VEIGA, Janaína de Lima. A Questão Ética da Relação dos Homens com os Animais na Perspectiva Schopenhaueriana. Dissertação de Mestrado defendida no Programa de Pós-Graduação em Filosofia da Pontifícia Universidade Católica do Paraná. Curitiba-PR, 2011.

79. SÁ MOREIRA, Fernando de. Ethos e Pathos em Schopenhauer e Nietzsche: Vida, Vontade e Ascetismo. Dissertação de Mestrado defendida no Programa de Pós-Graduação em Filosofia da Universidade Estadual do Oeste do Paraná. Toledo-PR, 2011.

8o. MAFALDA, Rodrigo. A Idéia de Formação - Continuidades e Rupturas entre Nietzsche e Schopenhauer. Dissertação de Mestrado defendida no Programa de Pós-Graduação em Educação da Universidade Federal de Santa Catarina. Florianópolis-SC, 2011.

81. NASCIMENTO, Dax Fonseca Moraes Paes. "Liberdade e Negação da Vontade: Análise do Ser-Livre como Representação e na Angústia". Tese de Doutorado defendida no Programa de Pós-Graduação em Filosofia da Universidade Federal da Paraíba. João Pessoa-PB, 2011.

82. ALVES, José Clerison Santos. Schopenhauer e a Recusa da Fundamentação Racional da Moral. Dissertação de Mestrado defendida no Programa de Pós-Graduação em Filosofia da Universidade Federal da Bahia. Salvador-BA, 2011.

83. BRITTO, Wilson Vieira de. O Fenômeno da Compaixão na Ética de Arthur Schopenhauer. Dissertação de Mestrado defendida no Programa de Pós-Graduação em Filosofia da Faculdade Jesuíta de Filosofia e Teologia. Belo Horizonte-MG, 2011.

84. LIMA, Dalton Oscar Walbruni. O Aprendizado da Vontade e as Dores do Mundo. Dissertação de Mestrado defendida no Programa de Pós-Graduação em Educação da Universidade Federal do Ceará. Fortaleza-CE, 2011.

85. PEREIRA, Gilmara Coutinho. A Compaixão como Via de Negação da Vontade em Schopenhauer. Dissertação de Mestrado defendida no Programa de Pós-Graduação em Filosofia da Universidade Federal da Paraíba. João Pessoa-PB, 2011 .

86. SILVA, Antunes Ferreira da. Os Conceitos de Vontade e Representação no Entendimento do Mundo segundo Arthur Schopenhauer. Dissertação de Mestrado defendida no Programa de Pós-Graduação em Filosofia da Universidade Federal da Paraíba. João Pessoa-PB, 2011.

87. ALMEIDA, Martha de. "A Tragédia nas Teorias de Schopenhauer e Nietzsche". Tese de Doutorado defendida no Programa de Pós-Graduação em Filosofia da Universidade do Estado do Rio de Janeiro. Rio de JaneiroRJ, 2011.

88. JÚNIOR, Ruy de Carvalho Rodrigues. Schopenhauer: Uma Filosofia do Limite. Tese de Doutorado defendida no Programa de Pós-Graduação em Filosofia da Pontifícia Universidade Católica de São Paulo. São PauloSP, 2011. 
136 | Schopenhauer no Brasil: Análise da presença schopenhaueriana em teses de doutorado e dissertações de mestrado de 1987 a 2018

89. LIMA, Antonio Marcos Vaz de. Mitleid, a Compaixão como Fundamento da Moral no Pensamento de Arthur Schopenhauer. Dissertação de Mestrado defendida no Programa de Pós-Graduação em Ética e Epistemologia da Fundação Universidade Federal do Piauí. Teresina-PI, 2012.

90. BASTOS, Eduardo Reina. Estética Afirmativa em Arthur Schopenhauer. Dissertação de Mestrado defendida no Programa de Pós-Graduação em Estética e Filosofia da Arte da Universidade Federal de Ouro Preto. Ouro Preto-MG, 2012.

91. DAMASCENO, Francisco William Mendes. Ética e Metafísica em Schopenhauer: A Coexistência da Vontade Livre com a Necessidade das Ações. Dissertação de Mestrado defendida no Programa de Pós-Graduação em Filosofia da Universidade Federal do Ceará. Fortaleza-CE, 2012.

92. LOPES, Ricardo Farias Martins. A Contemplação Estética como Ideal do Nirvana Búdico. Dissertação de Mestrado defendida no Programa de Pós-Graduação em Filosofia da Universidade Estadual Paulista Júlio de Mesquita Filho. Marília-SP, 2012.

93. BREDA, Juliana Fernandes. Amor e Morte em Schopenhauer. Dissertação de Mestrado defendida no Programa de Pós-Graduação em Filosofia da Universidade Estadual Paulista Júlio de Mesquita Filho. Marília-SP, 2012.

94. POYARES, Marianna Monteiro Drumond. O Nó do Mundo: Sobre o Conceito de Indivíduo em Schopenhauer. Dissertação de Mestrado defendida no Programa de Pós-Graduação em Filosofia da Universidade de São Paulo. São Paulo-SP, 2012.

95. PASTORE, Jassanan Amoroso Dias. O Trágico: Schopenhauer e Freud. Dissertação de Mestrado defendida no Programa de Pós-Graduação em Ciências da Religião da Pontifícia Universidade Católica de São Paulo. São Paulo-SP, 2012.

96. VIANA, Jeime Gonçalves. A Experiência Estética como Via de Acesso ao Conhecimento da Vontade em Schopenhauer. Dissertação de Mestrado defendida no Programa de Pós-Graduação em Filosofia da Universidade do Vale do Rio dos Sinos. São Leopoldo-RS, 2012.

97. DURANTE, Felipe dos Santos . Virtude, Direito, Moralidade e Justiça em Schopenhauer. Dissertação de Mestrado defendida no Programa de Pós-Graduação em Filosofia da Universidade Estadual de Campinas. Campinas-SP, 2012.

98. SANTOS, Josevan Dutra dos. Uma Discussão sobre Filogênese Kant-Goethe-Schopenhauer na Constituição do Conceito Forma-Paisagem e o seu Impacto na Geografia Humboldtiana. Dissertação de Mestrado defendida no Programa de Pós-Graduação em Geografia da Universidade Estadual de Campinas. CampinasSP, 2012.

99. PETRICH, Lademir Renato. O Retorno do Discurso Religioso em Arthur Schopenhauer como Expressão da Limitação Metafísica. Tese de Doutorado defendida no Programa de Pós-Graduação em Ciência da Religião da Universidade Federal de Juiz de Fora. Juiz de Fora-MG, 2012.

10o. FRAGOSO, Flora Bezerra da Rocha. Considerações sobre os Livros I e II de "O Mundo como Vontade e como Representação". Dissertação de Mestrado defendida no Programa de Pós-Graduação em Filosofia da Universidade Estadual do Ceará. Fortaleza-CE, 2013.

101. DEBONA, Vilmar. A Outra Face do Pessimismo: Entre Radicalidade Ascética e Sabedoria de Vida. Tese de Doutorado defendida no Programa de Pós-Graduação em Filosofia da Universidade de São Paulo. São Paulo-SP, 2013.

102. PICOLI, Gleisy Tatiana. Projeto Schopenhaueriano de Soteriologia. Dissertação de Mestrado defendida no Programa de Pós-Graduação em Filosofia da Universidade Estadual de Campinas. Campinas-SP, 2013.

103. SILVA, Luan Correa da. A Filosofia da Música como Filosofia Primeira: O Sentido Metafísico da Música em Schopenhauer. Dissertação de Mestrado defendida no Programa de Pós-Graduação em Filosofia da Universidade Federal de Santa Catarina. Florianópolis-SC, 2013. 
104. OlIVEIRA, Joao Roberto de. A Música como Superação do Pessimismo na Estética de Schopenhauer. Dissertação de Mestrado defendida no Programa de Pós-Graduação em Estética e Filosofia da Arte da Universidade Federal de Ouro Preto. Ouro Preto-MG, 2013.

105. OLIVEIRA, Andre Henrique Mendes Viana de. Dos Fenômenos ao Nada: Um Estudo sobre a Liberdade em Schopenhauer. Dissertação de Mestrado defendida no Programa de Pós-Graduação em Filosofia da Fundação Universidade Federal do Piauí. Teresina-PI, 2013.

106. CARVALHO, Diego Uchoa Souza. Os Conceitos de Representação em Schopenhauer. Dissertação de Mestrado defendida no Programa de Pós-Graduação em Filosofia da Universidade Federal da Paraíba. João Pessoa-PB, 2013.

107. WEBBER, Anderson Vieira de Lima. Metafísica de Schopenhauer enquanto Filosofia Prática. Dissertação de Mestrado defendida no Programa de Pós-Graduação em Filosofia da Universidade do Vale do Rio dos Sinos. São Leopoldo-RS, 2013.

108. ZINANI, Carlos Eduardo. Schopenhauer e a Educação. Dissertação de Mestrado defendida no Programa de Pós-Graduação em Educação da Universidade de Caxias do Sul. Caxias do Sul-RS, 2013.

109. MOURA, Carlos Alberto Leite de. Insubordinação no Drama Cósmico: Uma Reflexão sobre a Sabedoria de Vida em Arthur Schopenhauer. Dissertação de Mestrado defendida no Programa de Pós-Graduação em Filosofia da Faculdade de São Bento. São Paulo-SP, 2013.

110. SANTOS, Elcio Jose dos. Sobre o Papel da Causalidade na Crítica de Schopenhauer à Doutrina Kantiana das Categorias da Crítica da Razão Pura. Dissertação de Mestrado defendida no Programa de Pós-Graduação em Filosofia da Universidade Federal do Paraná. Curitiba-PR, 2013.

111. PAULA, Wander Andrade de. Nietzsche e a Transfiguração do Pessimismo Schopenhaueriano: A Concepção de Filosofia Trágica. Tese de Doutorado defendida no Programa de Pós-Graduação em Filosofia da Universidade Estadual de Campinas. Campinas-SP, 2013.

112. TORRES, Joel Neres. Sofrimento, Conhecimento de Si e Corpo em Schopenhauer. Dissertação de Mestrado defendida no Programa de Pós-Graduação em Filosofia da Universidade Federal do Pará. Belém-PA, 2013.

113. PAULA, Iacana Lopes de Rezende E. Entre Kant e Schopenhauer: Um Diálogo sobre a Moral e o Direito. Dissertação de Mestrado defendida no Programa de Pós-Graduação em Direito da Universidade Federal de Minas Gerais. Belo Horizonte-MG, 2014.

114. SANTOS, Tarcisio Alves dos. A Compaixão como Fundamentação Moral em Schopenhauer. Dissertação de Mestrado defendida no Programa de Pós-Graduação em Filosofia da Universidade Federal do Rio Grande do Norte. Natal-RN, 2014.

115. SOUSA, Karla Samara dos Santos. Sofrimento e Lucidez: Schopenhauer e a Filosofia da Imanência no Dhammapada. Dissertação de Mestrado defendida no Programa de Pós-Graduação em Ciências das Religiões da Universidade Federal da Paraíba. João Pessoa-PB, 2014.

116. SOUZA, Gabriela Nascimento. A Poesia Trágica como uma Manifestação do Sublime Dinâmico em Schopenhauer: Uma Exemplificação a partir da Obra As Flores do Mal de Baudelaire. Dissertação de Mestrado defendida no Programa de Pós-Graduação em Filosofia da Universidade Federal Fluminense. Niterói-RJ, 2014.

117. FILHO, Paulo de Tarso Rocha. Os Princípios do Sofrimento Humano em Schopenhauer e Freud. Dissertação de Mestrado defendida no Programa de Pós-Graduação em Filosofia da Universidade Federal da Paraíba. João Pessoa-PB, 2014.

118. LIMA, Ana Paula de Araujo. A Compaixão como uma Ética do Reconhecimento em Schopenhauer. Dissertação de Mestrado defendida no Programa de Pós-Graduação em Filosofia da Fundação Universidade Federal do Piauí. Teresina-PI, 2014. 
138 | Schopenhauer no Brasil: Análise da presença schopenhaueriana em teses de doutorado e dissertações de mestrado de 1987 a 2018

119. DALCOL, Monica Saldanha. A Compaixão como Fundamento da Moral em Schopenhauer. Dissertação de Mestrado defendida no Programa de Pós-Graduação em Filosofia da Universidade Federal de Santa Maria. Santa Maria-RS, 2014.

120. MEDEIROS, Gabriel Heidrich. A Compaixão em Nietzsche e Schopenhauer: seu Valor e sua Crítica. Dissertação de Mestrado defendida no Programa de Pós-Graduação em Filosofia da Universidade Federal de Pelotas. Pelotas-RS, 2014.

121. FRANCO, Eduardo Ferraz. A Unidade Metafísica do Ser e a Relação entre os Humanos e os demais Animais no Pensamento de Schopenhauer. Dissertação de Mestrado defendida no Programa de Pós-Graduação em Filosofia da Universidade Federal de Goiás. Goiânia-GO, 2014.

122. SOARES, Vinicius de Castro. Teleologia e Vontade em Schopenhauer. Dissertação de Mestrado defendida no Programa de Pós-Graduação em Filosofia da Universidade de São Paulo. São Paulo-SP, 2014.

123. SOUZA, Eduardo Ramos Coimbra de. Schopenhauer e os Conhecimentos Intuitivo e Abstrato. Dissertação de Mestrado defendida no Programa de Pós-Graduação em Filosofia da Universidade Estadual Paulista Júlio de Mesquita Filho. Marília-SP, 2014.

124. FILHO, Rogerio Moreira Orrutea. Dos Fundamentos do Direito de Propriedade na Filosofia de Schopenhauer. Dissertação de Mestrado defendida no Programa de Pós-Graduação em Filosofia da Universidade Estadual de Londrina. Londrina-PR, 2014.

125. PRADO, Jorge Luis Palicer do. Schopenhauer: A Metáfora da Vontade como Coisa-em-si. Dissertação de Mestrado defendida no Programa de Pós-Graduação em Filosofia da Universidade Estadual de Londrina. Londrina-PR, 2014.

126. ALONSO, Rodrigo Braga. As Forças Naturais na Obra de Schopenhauer. Dissertação de Mestrado defendida no Programa de Pós-Graduação em Filosofia da Universidade de São Paulo. São Paulo-SP, 2015.

127. SILVA, Gabriel Valladao. Cogito Ergo Volo : Para uma Fundamentação Epistemológica da Metafísica da Vontade Schopenhaueriana. Dissertação de Mestrado defendida no Programa de Pós-Graduação em Filosofia da Universidade Estadual de Campinas. Campinas-SP, 2015.

128. SCHAEFER, Leonardo Ritter. Natureza e Otimismo: Sobre Dor e Sofrimento em Arthur Schopenhauer. Dissertação de Mestrado defendida no Programa de Pós-Graduação em Filosofia da Pontifícia Universidade Católica do Rio Grande do Sul. Porto Alegre-RS, 2015.

129. VERAS, Roberto Pereira. Schopenhauer e os Upanishads: Vontade e Representação na Tradição Indiana. Dissertação de Mestrado defendida no Programa de Pós-Graduação em Ciências das Religiões da Universidade Federal da Paraíba. João Pessoa-PB, 2015.

130. FERREIRA, Gustavo Augusto da Silva. Ética e Eudemonologia em Arthur Schopenhauer. Dissertação de Mestrado defendida no Programa de Pós-Graduação em Filosofia da Universidade Estadual do Ceará. Fortaleza-CE, 2015.

131. FREITAS, Gildete dos Santos de. A Relação entre Vontade e Representação na Estética de Nietzsche e Schopenhauer. Tese de Doutorado defendida no Programa de Pós-Graduação em Filosofia da Universidade Federal de Minas Gerais. Belo Horizonte-MG, 2015.

132. LEMOS, Anerson Goncalves de. Os Sentidos da Felicidade: Uma Introdução ao Estudo da Metafísica da Felicidade e da Sabedoria de Vida em Schopenhauer. Dissertação de Mestrado defendida no Programa de Pós-Graduação em Filosofia da Universidade Federal de Santa Maria. Santa Maria-RS, 2015.

133. SILVA, Maria de Fatima. Moda ou Arte? O Caso das Sandálias Jailson Marcos à Luz da Filosofia de Schopenhauer. Dissertação de Mestrado Profissional defendida no Programa de Pós-Graduação em Gestão Empresarial da Faculdade Boa Viagem. Recife-PE, 2015. 
134. SAPELLI, Carlos. Schopenhauer, Teoria Psicanalítica e a Questão do Sofrimento. Dissertação de Mestrado defendida no Programa de Pós-Graduação em Filosofia da Pontifícia Universidade Católica do Paraná. Curitiba-PR, 2015.

135. TEIXEIRA, Nathan Menezes Amarante. Do Livre Jogo Cognitivo ao Modo de Consideração Genial: A Experiência Estética em Kant e o Conhecimento Estético em Schopenhauer. Dissertação de Mestrado defendida no Programa de Pós-Graduação em Filosofia da Universidade Federal Fluminense. Niterói-RJ, 2015 .

136. BASSOLI, Selma Aparecida. A Negação da Vontade como um Efeito da Graça: A Redenção na Concepção de Schopenhauer. Tese de Doutorado defendida no Programa de Pós-Graduação em Filosofia da Universidade de São Paulo. São Paulo-SP, 2015.

137. SOARES, Daniel Quaresma Figueira. Nietzsche e a Autossuperação da Filosofia da Vontade: Uma Interpretação sobre o Papel da Recepção de Schopenhauer no Percurso da Obra Nietzschiana. Tese de Doutorado defendida no Programa de Pós-Graduação em Filosofia da Universidade de São Paulo. São Paulo-SP, 2015.

138. MENDONCA, Mauricio Arruda. Kafka e Schopenhauer: Zonas de Vizinhança. Tese de Doutorado defendida no Programa de Pós-Graduação em Letras da Universidade Estadual de Londrina. Londrina-PR, 2015.

139. PANAGIOTIDOU, Jose David Alvaro de Sousa. Metafísica Pessimista e Eudemonologia na Filosofia de Schopenhauer. Dissertação de Mestrado defendida no Programa de Pós-Graduação em Filosofia da Universidade Estadual do Ceará. Fortaleza-CE, 2015.

140. MENDONCA, Marinella Morgana de. A Dimensão Ética do Corpo Nos Pensamentos de Schopenhauer e de Freud. Tese de Doutorado defendida no Programa de Pós-Graduação em Filosofia da Universidade Federal de Minas Gerais. Belo Horizonte-MG, 2015.

141. FERNANDES, Maria Gomes. Sobre as Contribuições do Pensamento Oriental na Teoria Ética de Arthur Schopenhauer. Dissertação de Mestrado defendida no Programa de Pós-Graduação em Filosofia da Fundação Universidade Federal do Piauí. Teresina-PI, 2015.

142. DAMBROS, Eli Berto. Schopenhauer: A Práxis Otimista no Contexto do Pessimismo Metafísico. Dissertação de Mestrado defendida no Programa de Pós-Graduação em Filosofia da Pontifícia Universidade Católica do Paraná. Curitiba-PR, 2015.

143. SÁ MOREIRA, Fernando de. Do Caráter do Mundo ao Homem enquanto Caráter: Uma Investigação das Doutrinas de Identidade Pessoal em Schopenhauer e Nietzsche. Tese de Doutorado defendida no Programa de Pós-Graduação em Filosofia da Pontifícia Universidade Católica do Paraná. Curitiba-PR, 2015.

144. NASCIMENTO, Fabricio Christian do. As Criticas de Schopenhauer à Filosofia Moral Kantiana. Dissertação de Mestrado defendida no Programa de Pós-Graduação em Filosofia da Universidade Federal de Santa Catarina. Florianópolis-SC, 2015.

145. GUIMARAES, Jose Luis de Barros. Da Tragicidade da Vida ao Sublime da Existência: Schopenhauer e o Papel da Arte na Formação do Caráter. Dissertação de Mestrado defendida no Programa de Pós-Graduação em Filosofia da Fundação Universidade Federal do Piauí. Teresina-PI, 2015.

146. ROSA, Marcelo Ribeiro. Sobre a Tragédia, o Trágico e a Experiência do Negativo em Schopenhauer. Dissertação de Mestrado defendida no Programa de Pós-Graduação em Filosofia da Universidade Estadual de Londrina. Londrina-PR, 2015.

147. SANTOS, Flaviano Costa. Ética da Compaixão: Uma Visão Não Pessimista de Schopenhauer. Dissertação de Mestrado defendida no Programa de Pós-Graduação em Filosofia da Universidade Federal da Paraíba. João Pessoa-PB, 2016.

148. DIAS, Sara Pereira. A Compreensão de Schopenhauer da Coisa em Si. Dissertação de Mestrado defendida no Programa de Pós-Graduação em Filosofia da Universidade de São Paulo. São Paulo-SP, 2016. 
140 | Schopenhauer no Brasil: Análise da presença schopenhaueriana em teses de doutorado e dissertações de mestrado de 1987 a 2018

149. MACEDO, Andre Motta. "Razão Instrumental e Vontade: Max Horkheimer e o Pessimismo Metafísico de Arthur Schopenhauer. Dissertação de Mestrado defendida no Programa de Pós-Graduação em Filosofia da Universidade Federal de Uberlândia. Uberlândia-MG, 2016.

150. JUNIOR, Waldir Severiano de Medeiros. A Liberdade da Vontade e o Problema da Condição de Possibilidade da Responsabilização Jurídica: Um Estudo da Posição de Kant em Contraposição à Crítica de Schopenhauer. Dissertação de Mestrado defendida no Programa de Pós-Graduação em Direito da Universidade Federal de Minas Gerais. Belo Horizonte-MG, 2016.

151. MEDEIROS, Luana Oliveira. A Compaixão como Fenômeno Ético Originário da Moral e a sua Necessidade Metafísica. Dissertação de Mestrado defendida no Programa de Pós-Graduação em Filosofia da Universidade Federal do Paraná. Curitiba-PR, 2016.

152. LINS, Livia Ribeiro. As Vias de Negação da Vontade em Schopenhauer. Dissertação de Mestrado defendida no Programa de Pós-Graduação em Filosofia da Universidade Federal Rural do Rio de Janeiro. SeropédicaRJ, 2016.

153. PEDROSO, Michael Peterson Olano Morgantti. O Conhecimento enquanto Afirmação da Vontade de Vida: Um Estudo acerca da Dialética Erística de Arthur Schopenhauer. Dissertação de Mestrado defendida no Programa de Pós-Graduação em Filosofia da Universidade de Brasília. Brasília-DF, 2016.

154. SOUZA, Jacimar Cruz de. O Significado Metafísico da Ética da Compaixão em Schopenhauer. Dissertação de Mestrado defendida no Programa de Pós-Graduação em Filosofia da Faculdade Jesuíta de Filosofia e Teologia. Belo Horizonte-MG, 2016.

155. RUSSO, Allan Cristian Mota. A Metafísica do Belo e a Tragédia em Schopenhauer. Dissertação de Mestrado defendida no Programa de Pós-Graduação em Filosofia da Pontifícia Universidade Católica de São Paulo. São Paulo-SP, 2016.

156. SILVA, Julianne Teixeira E. Vislumbrando a Representação da Informação à Luz da Teoria do Conhecimento: de Platão a Schopenhauer. Tese de Doutorado defendida no Programa de Pós-Graduação em Ciência da Informação da Universidade Federal da Paraíba. João Pessoa-PB, 2016.

157. SILVA, Iasmim Cristina Martins da. O Drama do Gênio na Metafísica do Belo de Schopenhauer: Sua mais Alta Expressão no "Torquato Tasso" de Goethe. Dissertação de Mestrado defendida no Programa de PósGraduação em Filosofia da Universidade Federal Rural do Rio de Janeiro. Seropédica-RJ, 2016.

158. DURANTE, Felipe dos Santos. Direito Natural e Direitos Fundamentais: A Atualidade de Schopenhauer para o Debate acerca dos Direitos Humanos. Tese de Doutorado defendida no Programa de Pós-Graduação em Filosofia da Universidade Estadual de Campinas. Campinas-SP, 2017.

159. OLIVEIRA, Sidnei de. Richard Wagner: O Músico Esteta a partir da Filosofia Schopenhaueriana. Tese de Doutorado defendida no Programa de Pós-Graduação em Filosofia da Universidade Estadual de Campinas. Campinas-SP, 2017.

16o. PAMPLONA, Simiao Severino. A Possibilidade da Felicidade em Schopenhauer. Dissertação de Mestrado defendida no Programa de Pós-Graduação em Filosofia da Universidade Federal do Rio Grande do Norte. Natal-RN, 2017.

161. SILVA, Ronaldo Pizzatto do Nascimento. Schopenhauer e a Ética da Compaixão: As Consequências da Ação Compassiva para a "Formação" do Caráter. Dissertação de Mestrado defendida no Programa de PósGraduação em Filosofia da Fundação Universidade Federal do Piauí. Teresina-PI, 2017.

162. COMARELLA, Luiza Tomich. Intuição Empírica e Intuição Estética na Filosofia de Schopenhauer. Dissertação de Mestrado defendida no Programa de Pós-Graduação em Filosofia da Universidade Federal do Paraná. Curitiba-PR, 2017.

163. SILVA, Luan Correa da. Metafísica Prática em Schopenhauer. Tese de Doutorado defendida no Programa de Pós-Graduação em Filosofia da Universidade Federal de Santa Catarina. Florianópolis-SC, 2017. 
164. SANTOS, Katia Cilene da Silva. A Antinomia da Teoria do Conhecimento de Schopenhauer. Tese de Doutorado defendida no Programa de Pós-Graduação em Filosofia da Universidade de São Paulo. São Paulo-SP, 2017.

165. LIMA, Felipe Cardoso Martins. As Formas de Conhecimento Intuitivo e o Problema da Liberdade em Schopenhauer. Tese de Doutorado defendida no Programa de Pós-Graduação em Filosofia da Universidade Federal de Santa Catarina. Florianópolis-SC, 2017.

166. SOUZA, Gabriel Saikoski de. O Canto de Dionísio vem de Longe ou sobre como Chegar ao 'Nascimento da Tragédia' através de Schopenhauer e Wagner. Dissertação de Mestrado defendida no Programa de PósGraduação em Filosofia da Universidade Federal de Ouro Preto. Ouro Preto-MG, 2017.

167. ALMEIDA, Camila Berehulka de. Vínculo e Relação entre a Metafísica do Belo e a Ética de Schopenhauer. Dissertação de Mestrado defendida no Programa de Pós-Graduação em Filosofia da Universidade Estadual de Londrina. Londrina-PR, 2017.

168. CUENCA, Juliana dos Reis. Schopenhauer: A Intuição Primordial de Significação do Mundo para além do Argumento da Analogia. Dissertação de Mestrado defendida no Programa de Pós-Graduação em Filosofia da Universidade Estadual de Londrina. Londrina-PR, 2017.

169. VALENTE, Lucas Lazarini. Objeto e Objetivação da Vontade em Schopenhauer. Dissertação de Mestrado defendida no Programa de Pós-Graduação em Filosofia da Universidade Estadual de Campinas. CampinasSP, 2017.

170. PEREIRA, Fernando Vinicius Mendes. A Primazia da Vontade sobre a Razão em Schopenhauer. Dissertação de Mestrado defendida no Programa de Pós-Graduação em Filosofia da Universidade Estadual de Maringá. Maringá-PR, 2017.

171. MESQUITA, Fabio Luiz de Almeida. Schopenhauer e a Índia: Apropriações e Influências da Asiatisches Magazin, Mythologie Des Indous e Asiatick Researches no Período de Gênese da Filosofia Schopenhaueriana. Tese de Doutorado defendida no Programa de Pós-Graduação em Filosofia da Universidade de São Paulo. São Paulo-SP, 2018.

172. FIGUEIROA, Danilo da Silva. A Natureza da Compaixão em Schopenhauer: Mistério e Cotidiano. Dissertação de Mestrado defendida no Programa de Pós-Graduação em Filosofia da Universidade Federal Rural do Rio de Janeiro. Seropédica-RJ, 2018.

173. NUNES, Luiz Diego Barbosa. Do Drama à Música: A Influência de Schopenhauer em Wagner. Dissertação de Mestrado defendida no Programa de Pós-Graduação em Filosofia da Universidade Estadual do Ceará. Fortaleza-CE, 2018.

174. JUNIOR, Dilermando Aniceto Eleuterio. Sabedoria de Vida em Schopenhauer: Realismo Pragmático. Dissertação de Mestrado defendida no Programa de Pós-Graduação em Filosofia da Universidade Federal do Paraná. Curitiba-PR, 2018.

175. FILHO, Antonio Francisco da Silva. Eudemonologia: A Possibilidade de se Viver menos Infeliz no Mundo segundo Arthur Schopenhauer. Dissertação de Mestrado defendida no Programa de Pós-Graduação em Filosofia da Universidade Federal da Paraíba. João Pessoa-PB, 2018.

176. PICOLI, Gleisy Tatiana. Os Limites da Linguagem e o Místico na Filosofia de Arthur Schopenhauer . Tese de Doutorado defendida no Programa de Pós-Graduação em Filosofia da Universidade Estadual de Campinas. Campinas-SP, 2018.

177. ROSATO, Gustavo Rodrigues. A Filosofia de Corpo, Vontade e Representação em Arthur Schopenhauer". Dissertação de Mestrado defendida no Programa de Pós-Graduação em Filosofia da Universidade Federal de Uberlândia. Uberlândia-MG, 2018.

178. SALES, Erinaldo de Oliveira. Arquitetura e Literatura no Sistema das Artes. Tese de Doutorado defendida no Programa de Pós-Graduação em Arquitetura e Urbanismo da Universidade de Brasília. Brasília-DF, 2018. 
142 | Schopenhauer no Brasil: Análise da presença schopenhaueriana em teses de doutorado e dissertações de mestrado de 1987 a 2018

179. PACIFICO, Bruno Victor Brito. A Superioridade da Forma Musical diante da Poesia de Schopenhauer. Dissertação de Mestrado defendida no Programa de Pós-Graduação em Filosofia da Universidade Federal Fluminense. Niterói-RJ, 2018.

180. MEDEIROS, Victor Hugo Melo de. A Razão do Sábio não temer a Morte na Filosofia de Arthur Schopenhauer. Dissertação de Mestrado defendida no Programa de Pós-Graduação em Filosofia da Universidade Federal do Rio Grande do Norte. Natal-RN, 2018.

181. DAMASCENO, Francisco William Mendes. Schopenhauer: da Metafísica à Política. Tese de Doutorado defendida no Programa de Pós-Graduação em Filosofia da Universidade Federal do Ceará. Fortaleza-CE, 2018 . 